
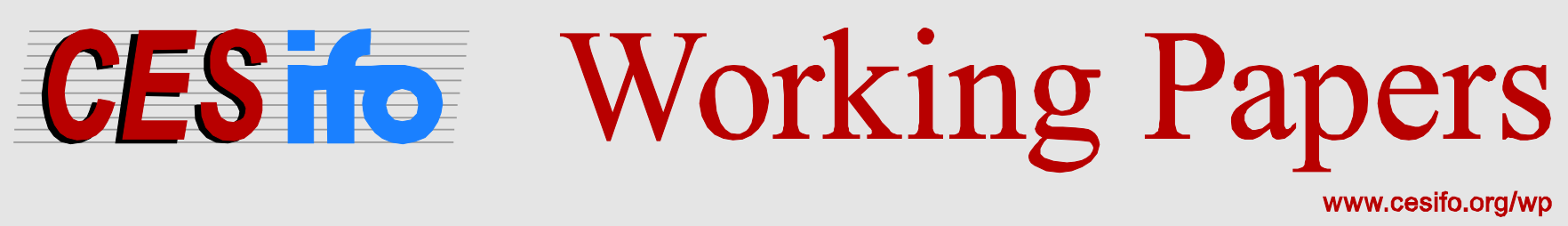

\title{
Imported-input Trade Liberalization and Firms' Export Performance in China: Theory and Evidence
}

\author{
Haichao Fan \\ Edwin L.-C. Lai \\ Han Steffan Qi
}

CESIFO WORKING PAPER NO. 5828

CATEGORY 8: TRADE POLICY

MARCH 2016

An electronic version of the paper may be downloaded

- from the SSRN website:

- from the RePEc website:

- from the CESifo website:

wWw.SSRN.com

www.RePEc.org

www.CESifo-group.org/wp

ISSN 2364-1428

CESifo 


\title{
Imported-input Trade Liberalization and Firms' Export Performance in China: Theory and Evidence
}

\begin{abstract}
The literature on trade liberalization has recently shifted its attention from trade liberalization in imported final goods to studying the effects of trade liberalization in imported intermediate inputs. This emphasis fits very well the trade liberalization experience of China following its accession to the WTO in 2001. We build a multi-sector heterogenous-firm model with trade in both intermediate goods and final goods, and we ask: How do final-goods producers respond to trade liberalization in imported inputs? Do they respond differently across sectors? How do firms respond differently to trade liberalization in imported-outputs instead? We decompose the total effect of trade liberalization into those caused by inter-sectoral resource allocation (IRA) and by within-sector selection of firms according to productivity (which we call Melitz selection effect). It is the IRA effect that gives rise to differential impacts of trade liberalization in different sectors. These impacts include changes in the probability of entry into the export market, the fraction of firms that export and the share of export revenue. We test our hypotheses using Chinese firm-level data for the years after China's accession to WTO in 2001. The results generally support our hypotheses.
\end{abstract}

JEL-Codes: F120, F140.

Keywords: imported-input liberalization, firms’ export performance, China.

Haichao Fan

School of International Business

Administration, Shanghai University of

Finance and Economics

Shanghai / China

fan.haichao@mail.shufe.edu.cn
Edwin L.-C. Lai*

Department of Economics Hong Kong University of Science and Technology, Clear Water Bay Kowloon / Hong Kong elai@ust.hkoredwin.l.lai@gmail.com

\author{
Han Steffan Qi \\ Department of Economics \\ Hong Kong Baptist University \\ Kowloon Tong \\ Kowloon / Hong Kong \\ steffan@hkbu.edu.hk
}

*corresponding author 
January 31, 2016

We would like to thank participants in seminars in the Johns Hopkins SAIS, Paris School of Economics, Graduate Institute in Geneva, ECARES in Brussels, Chinese University of Hong Kong, City University of Hong Kong, Shanghai University of Finance and Economics, ETH Zurich, Hokkaido University, as well as conference participants in Tsinghua University International Trade Workshops in 2010 and 2011, Australian Trade Workshop 2012, AEA Annual Conference 2013, Duke University Conference on the Chinese Economy 2013, IEA World Congress 2014, China Conference in KU (Leuven) in July 2015, for helpful comments. The work in this paper has been supported by the Research Grants Council of Hong Kong, China (General Research Funds Project no. 642210 and 691813) and by the Shanghai Pujiang Program (15PJC041). 


\section{Introduction}

The literature on trade liberalization has recently shifted its attention from trade liberalization in imported final goods to studying the effects of trade liberalization in imported intermediate inputs. This emphasis fits very well the trade liberalization experience of China following its accession to the WTO in 2001. We build a multi-sector heterogenous-firm model with trade in both intermediate goods and final goods, and we ask: How do final-goods producers' entry, exit, production and exporting decisions respond to trade liberalization in imported intermediate goods? Do they respond differently across sectors? How do these firm responses affect the aggregate exporting performance? How do firms respond differently to trade liberalization in imported-outputs as opposed to imported-inputs? Then, we test our hypotheses using Chinese firm-level data for the years after China's accession to WTO in 2001.

How firms' behaviors are affected by bilateral trade liberalization of final goods have been analyzed by Melitz (2003) and many follow-up papers. However, not all episodes of trade liberalization are bilateral in nature and many of them resulted in mainly tariff cuts on intermediate goods. Firms respond differently for different types of unilateral trade liberalization. When there is unilateral reduction of tariffs on imported final goods, the exporting firms in the domestic country are hurt, as foreign products become relatively cheaper and therefore more competitive in the domestic market. When there is unilateral reduction of tariffs on imported-inputs, the domestic final goods producers benefit from it as it reduces their costs. The recent literature in global value chain (e.g. Johnson and Noguera, 2012; Koopman, Wang and Wei, 2014) shows that trade of intermediate inputs becomes increasingly important in global trade. This prompts economists to switch their attentions to trade liberalization in intermediate goods. As we shall demonstrate in this paper, firms respond differently following unilateral trade liberalization in intermediate goods than that in final goods.

It is widely recognized that China has long enjoyed the most favored nation (MFN) treatment from its major trading partners prior to joining the WTO. ${ }^{1}$ Thus, China's accession to the WTO has been generally believed to be primarily unilateral reduction of import tariffs (see, for example, Fan, Li and Yeaple, 2015). This view can also be verified by Figure 2, which summarizes the trend of changes for different types of tariffs in China during the period 2001-2006. Chinese customs data show that the majority of Chinese imports were for intermediate goods rather than for final goods (see, for example, Fan, Gao, Li and Tuan, 2015). Refer to Figure A1 in the appendix. Intermediate goods and capital goods accounted for $74 \%$ and $19 \%$ respectively, and final goods accounted for only $4 \%$, of total value of imports of China during the period 2001-2006. Therefore, we think it is reasonable to assume that the main consequence of China's accession to the WTO is unilateral trade liberalization in intermediate inputs. Chinese final-good producers in general enjoyed the cost-saving in inputs associated with this episode of trade liberalization, and this paper shows that different sectors responded differently to this event.

To understand how different sectors respond differently to such unilateral trade liberalization in

\footnotetext{
${ }^{1}$ For some trading partners, the MFN treatment was somewhat precarious.
} 
imported inputs, we develop a model that incorporates Ricardian comparative advantage and Eaton and Kortum's (2002) type of selection of intermediate inputs into a multi-sector, two-country version of Melitz's (2003) monopolistic competition model with heterogenous firms. We use the model to explain how comparative advantage and economies of scale interact to sort sectors into ones in which only one of the countries produces (where there is inter-industry trade) and ones in which both countries produce (where there is intra-industry trade). We then analyze the effects of unilateral trade liberalization, with a special focus on imported-input trade liberalization. We decompose the total effect of trade liberalization into those caused by inter-sectoral resource allocation (which we call IRA effect) and by within-sector selection of firms according to productivity (which we call Melitz selection effect).

Following imported-input trade liberalization, all final-good firms enjoy cheaper intermediate goods. Melitz's selection effect predicts that, in each final-good sector, such liberalization tends to increase the productivity cutoff for survival and reduce the productivity cutoff for exporting within the sector, and this tends to increase the average productivity of the firms serving the domestic market in that sector. All sectors are affected equally. On the other hand, the IRA effect predicts that such liberalization leads to resources in the home country being reallocated from the outside good sector to the differentiatedgood sectors, but more towards the sectors with stronger comparative advantage. The IRA effect also tends to raise the productivity cutoff for survival and lower the productivity cutoff for exporting. However, the effect is larger, the stronger is the comparative advantage of a sector.

Thus, the interaction of the Melitz selection effect and the IRA effect causes firms in different sectors to respond differently to imported-input trade liberalization. The theory predicts that, for the sectors with stronger comparative advantage, the probability of entry into the export market for previously non-exporting firms, the change in the fraction of firms that export, and the change in the revenue share from exporting, are all higher. We test the hypotheses related to these reallocative effects of trade liberalization using Chinese firm-level data for the years 2001-2006, that is, around the time of China's accession to WTO in 2001. We choose China because its accession to the WTO has been widely recognized as primarily unilateral reduction of import tariffs and a vast majority of China's imports were intermediate goods in the covered period. We use the tariff data from the WTO database to estimate the industry-level imported-input tariffs and use the trade flow data from CEPII to estimate the industrylevel reveal comparative advantage (RCA) index to proxy for sectoral comparative advantage. ${ }^{2}$

The estimation results confirm the predictions of our theory. Our results are robust to various alternative econometric specifications and alternative measures of imported-input tariff reduction and RCA index. In addition, we show that our results are not driven by other potential mechanisms such as currency appreciation and Multi-Fibre Arrangement. We focus on how revealed comparative advantage (RCA) of the sector affects the effects of imported-input trade liberalization in that sector.

In addition, our model can as well be used to investigate other types of unilateral trade liberalization. Our theory predicts that unilateral trade liberalization in imported final goods, which we call importedoutput trade liberalization, results in the domestic final-good firms facing more competition from foreign firms, which leads to opposite effects on firms' exporting behaviors compared with imported-input trade

\footnotetext{
${ }^{2}$ The full name of CEPII is Centre d'Etudes Prospectives et d'Information Internationales.
} 
liberalization. We also verify this prediction in the empirical estimation of the model. Furthermore, reduction of tariffs on the domestic country's exported final goods reinforces domestic final-good firms' competitiveness in the foreign market; thus, it has a similar effect as imported-input trade liberalization. However, the effect reduction in export tariffs is not significant in our empirical estimation as China's accession to the WTO was mainly unilateral reduction of import tariffs, and so the variations in the changes of export tariffs are not large enough to yield statistically significant effects.

The theory part of our paper share some common features with a couple of papers in the literature. Like us, Okubo (2009) also introduces multiple sectors into the Melitz model, thus making it a hybrid of the multiple-sector Ricardian model and the Melitz model. The bulk of his analysis focuses on the two-sector case, in which he analyzes the general equilibrium effects, allowing for the endogenous determination of the relative wage. Bernard, Redding and Schott (2007) incorporate firm heterogeneity into a two-sector, two-country Heckscher-Ohlin model, and analyze how trade leads to the reallocation of resources, both within and across industries. Inter-sectoral resource reallocation changes the exante comparative advantage and provides a new source of welfare gains from trade as well as causes redistribution of income across factors. The structure of the model and the emphasis of our paper are quite different from these two papers. In contrast to these two papers, we have trade in both intermediate goods and final goods, and we incorporate the endogenous selection of intermediate inputs, and analyze the effects of imported-input trade liberalization on final-good firms' exporting behavior. Moreover, we carry out detailed empirical tests of the theory.

In the empirical literature, Alvarez and Lopez (2008) use a fixed effect approach to investigate the effects of trade liberalization on firm number, firm sizes and markups at the industry level. In their empirical estimation, both trade liberalization and comparative advantage are captured as dummy variables. Bombardini, Kurz and Morrow (2010) incorporate Ricardian comparative advantage and Melitz selection effect into a unified model, and use Chilean and Colombian plant-level data to investigate the relationship between firm productivity and exporting behavior. They adopt the peer firm's productivity as the measure of Ricardian comparative advantage. In contrast, we use detailed information of tariff reduction and revealed comparative advantage (RCA) of Chinese firms for our investigation, which yields empirical results that can be more readily compared with our theoretical predictions. Moreover, we analyze the effect on firms' exporting behavior following unilateral trade liberalization in imported intermediate goods.

Our paper also contributes to an emerging literature that relates the effects of improved access to imported intermediate inputs to superior firm performance. Dimensions in which superior performance are measured include improved total factor productivity (Amiti and Konings, 2007; Halpern, Koren and Szeidl, 2011; Gopinath and Neiman, 2014), upgrade in their product quality (Amiti and Khandelwal, 2013, Fan, Li and Yeaple, 2015; Bas and Strauss-Kahn, 2015), and product scope expansion (Goldberg, Khandelwal and Pavcnik, 2010). Most of these papers are based on partial equilibrium analysis. In contrast, we carry out a general equilibrium analysis and focus on the effects of imported-input trade liberalization on firms' export performance. Antras, Fort and Tintelnot (2014), which is the paper closest to ours in the literature, employ Eaton and Kortum's (2002) framework for the choice of intermediate 
goods from different sources to study the extensive and intensive margins of firms' global sourcing decisions. Despite the similarity in the modeling technique in the input-bundle choice, the focus of our paper is quite different from theirs. We are interested in firms' exporting response to reduction of trade costs for imported intermediate goods, while they are more interested in firms' choices of input bundles.

Finally, our paper is also related to the strand of literature that analyzes the difference between the effects of trade reforms in the final goods market and those in the intermediate goods market. Amiti and Konings (2007) show that, compared with output-tariff liberalization, trade liberalization in the intermediate-goods markets has a far more important impact on firms' productivity. On the other hand, De Locker, Goldberg, Khandelwal and Pavcnik (2015) analyze the difference between the effect of output-tariff liberalization and that of input-tariff liberalization on firm-product markups.

The paper is organized as follows. Section 2 presents a two-country, multi-sector model with heterogeneous firms, where there are trade in intermediate and final goods, and examines the properties of the global equilibrium. We analyze the pattern of specialization and trade and identify the existence of inter-industry trade as well as intra-industry trade. In section 3, we analyze the effects of trade liberalization, focusing on that of imported-inputs, and demonstrate how the IRA effect and Melitz selection effect interact in the two-way trade sectors, which differ from each other according to their strengths of comparative advantage. In section 4, we describe the specification of the empirical tests to be carried out, the data sources and the construction of the measures for the key variables such as tariffs and RCAs. In section 5, empirical tests of the propositions presented in section 3 are carried out. In Section 6, we carry out various robustness checks for the empirical estimations. Section 7 concludes.

\section{An Open-economy Model}

We consider a global economy with two countries: Home and Foreign. There are $L$ and $L^{*}$ consumers in Home and Foreign respectively, each supplying one unit of labor. We attach an asterisk to all the variables pertaining to Foreign. In the rest of this section, we main focus on deriving the equations and expressions for Home. The corresponding equations and expressions for Foreign are given analogously unless otherwise stated. The preferences of a representative consumer in Home is given by a nested Cobb-Douglas function:

$$
\begin{aligned}
\ln U & =\alpha \ln Q_{h}+\int_{0}^{1} \beta_{k} \ln Q_{k} d k \quad \text { with } \int_{0}^{1} \beta_{k} d k=1-\alpha \\
\text { and } Q_{k} & =\left(\int_{0}^{\theta_{k}} q_{k}(j)^{\rho} d j\right)^{\frac{1}{\rho}} \text { with } 0<\rho<1 ; 1<\sigma=\frac{1}{1-\rho}<\infty
\end{aligned}
$$

where $q_{k}(j)$ is the consumption of variety $j$ in differentiated final good sector $k$; $Q_{h}$ is the consumption of a homogeneous good; $\sigma$ is the elasticity of substitution between any pair of varieties within a differentiated final good sector; $\alpha$ is the share of expenditure on the homogenous good, $\beta_{k}$ is the share of expenditure on differentiated final good $k \in[0,1] ; \theta_{k}$ is the endogenously determined mass of varieties in differentiated-good sector $k$ (which may originate from Home or Foreign) available to consumers in Home. The representative consumer in Foreign has analogous preferences. 
There is only one factor input called labor. The homogeneous good is produced using labor according to a constant returns to scale technology, and the sector is under perfect competition. The labor productivity in the homogeneous good sector are respectively $A_{h}$ and $A_{h}^{*}$ in Home and Foreign. In the rest of the paper, we assume that the homogeneous good sector is sufficiently large so that the homogeneous good is produced in both countries. ${ }^{3}$ We also assume that there is no trade cost associated with the homogeneous good. Therefore free trade of homogeneous goods implies that the wage ratio is determined by relative labor productivity in the sector, i.e. $\omega \equiv \frac{w}{w^{*}}=\frac{A_{h}}{A_{h}^{*}}$, where $w$ denotes Home's wage and $w^{*}$ denotes Foreign's wage. Without loss of generality, we assume that $\frac{A_{h}}{A_{h}^{*}}=1$ and normalize by setting $w^{*}=1$. Therefore, in equilibrium $w=w^{*}=1$.

\section{Production of differentiated final goods}

In the differentiated-good sectors, firms are free to choose which sector they enter. Upon payment of the entry cost $f_{e}$, the firm earns the opportunity to make a random draw that determines the firmspecific component, $\varphi_{k}$, of the firm's total factor productivity. The total factor productivity of a firm in the differentiated-good sector $k$ is the product of two terms: one is a firm-specific, random variable $\varphi_{k}$, which follows a Pareto distribution $P(1, \gamma)=1-\left(\frac{1}{\varphi_{k}}\right)^{\gamma}$ where $\varphi_{k} \in[1, \infty]$ and $\gamma(>\sigma-1)$ is the shape parameter of the distribution; ${ }^{4}$ the other is $A_{k}$, which is exogenous and sector-specific. The total factor productivity of a firm is thus equal to $A_{k} \varphi_{k}$. We denote the sector-specific component of the relative total factor productivity by $a(k) \equiv a_{k} \equiv \frac{A_{k}}{A_{k}^{*}}$, and we index sectors in such a way that $a^{\prime}(k)>0$. The production function of a differentiated-good firm with total factor productivity $A_{k} \varphi_{k}$ is given by $A_{k} \varphi_{k} l^{1-\mu} M^{\mu}$, where $l$ denotes labor input; $M$ denotes the measure of an intermediate-input bundle, which is costlessly assembled from a continuum of intermediate inputs that are indexed by $z$ according to the production function:

$$
M=\left\{\int_{\Omega}[m(z)]^{\frac{\eta-1}{\eta}} d z+\int_{\Omega^{*}}[m(z)]^{\frac{\eta-1}{\eta}} d z\right\}^{\frac{\eta}{\eta-1}}
$$

where $m(z)$ is the quantity of intermediate input $z$. The set of intermediate inputs supplied by Home (Foreign) is denoted by $\Omega\left(\Omega^{*}\right)$. For a cost-minimizing differentiated-good firm, the unit price of an intermediate-input bundle is given by $P_{M}=\left[\int_{0}^{1} c_{m}(z)^{1-\eta} d z\right]^{\frac{1}{1-\eta}}$, where $c_{m}(z)$ is the lowest unit cost of intermediate input $z$ available to the firm. Intermediate inputs are produced using labor only. To a differentiated-good firm, the unit cost of an intermediate input $z$ depends on whether the input was purchased from a domestic supplier or from a foreign supplier. If the firm purchases input $z$ locally, its unit cost is equal to the wage of $1 / b$ units of labor, where $b$ is domestic country's realized labor productivity in producing intermediate good $z$. If the firm imports input $z$, then it must first pay a cost equal to the wage of $\tau_{i k} / b^{*}$ units of foreign labor, where $b^{*}$ is foreign country's realized labor productivity in producing intermediate $\operatorname{good} z$, and $\tau_{i k}(>1)$ is the iceberg trade cost for imported

\footnotetext{
${ }^{3}$ The sufficient condition is $\alpha>\max \left\{\frac{L}{L+L^{*}}, \frac{L^{*}}{L+L^{*}}\right\}$. However, this is just a sufficient, not necessary, condition. In general, we do not need such a strong assumption on $\alpha$, as each country usually both imports and exports differentiated goods. If trade in differentiated goods is close to balanced, $\alpha$ can be much smaller.

${ }^{4}$ The assumption $\gamma>\sigma-1$ ensures that, in equilibrium, the size distribution of firms has a finite mean.
} 
inputs in sector $k$, such that $\tau_{i k}$ units of goods have to be shipped from the source in order for one unit to arrive at the destination. Following Eaton and Kortum (2002) and Antras, Fort and Tintelnot (2014), we assume that Home's efficiency distribution in producing the intermediate inputs follows the Fréchet distribution:

$$
\operatorname{Pr}(b(z) \leq b)=e^{-T b^{-\lambda}}, \text { with } T>0
$$

where $T$ governs the state of technology in Home, while $\lambda$ determines the variability of labor productivity draws in both countries. Foreign's efficiency distribution in producing the intermediate goods follows the Fréchet distribution, with $T^{*}$ governing the state of technology in Foreign. The unit cost of each bundle of intermediate-inputs in sector $k$ faced by a Home differentiated-good producer is therefore given by:

$$
c_{k}=\zeta\left[T+T^{*}\left(\tau_{i k}\right)^{-\lambda}\right]^{-1 / \lambda}
$$

where $\zeta=\left[\Gamma\left(\frac{\lambda+1-\eta}{\lambda}\right)\right]^{1 /(1-\eta)}$ and $\Gamma($.$) is the Gamma function. Hence, the variable cost of final good$ production is equal to $\left[\frac{1}{\mu^{\mu}(1-\mu)^{1-\mu}}\right] \frac{\left(c_{k}\right)^{\mu}}{A_{k} \varphi_{k}}$. We assume that there is a fixed cost of final good production $f$, which is incurred in every period. The expression for $c_{k}^{*}$ is given analogously.

We assume the following: Home's final goods producers import only intermediate inputs, and export only final goods; Home's intermediate inputs producers export only intermediate inputs, and import nothing; Home's consumers import final goods directly from Foreign's firms. Analogous assumptions apply to Foreign. The variable $\tau_{i k}\left(\tau_{i k}^{*}\right)$ denotes the iceberg-cost-equivalent tariff on Home's (Foreign's) imported intermediate inputs; while $\tau_{x k}\left(\tau_{x k}^{*}\right)$ denotes the iceberg-cost-equivalent tariff on Home's (Foreign's) exported final goods. In other words, all trade costs are attributed to tariffs - transport costs are assumed to be zero.

The aggregate price index of final goods in sector $k$ sold in Home is given by

$$
P_{k}=\left[\int_{0}^{\theta_{k}} p_{k}(j)^{1-\sigma} d j\right]^{\frac{1}{1-\sigma}}
$$

where $p_{k}(j)$ denotes the price of variety $j$ in sector $k$. The analogous index for Foreign is $P_{k}^{*}$.

The subscript " $d k$ " pertains to a domestic firm serving the domestic market in sector $k$; the subscript " $x k$ " pertains to a domestic firm serving the foreign market in sector $k$; and the subscript " $k$ " pertains to sector $k$ regardless of who serves the market. Therefore, under monopolistic competition in sector $k$ the profit-maximizing price for a domestic firm serving the domestic market is given by $p_{d k}(j)=\frac{\left(c_{k}\right)^{\mu}}{\tilde{\rho} A_{k} \varphi_{k}(j)}$, where $\widetilde{\rho}=\frac{(\sigma-1) \mu^{\mu}(1-\mu)^{1-\mu}}{\sigma} .5$ But Home's final-good exporting firms will set higher prices in Foreign's market due to the existence of an iceberg trade cost $\tau_{x k}(>1)$. Therefore, the profit-maximizing price of a Home-produced good sold in Foreign is given by $p_{x k}(j)=\frac{\left(c_{k}\right)^{\mu} \tau_{x k}}{\widetilde{\rho} A_{k} \varphi_{k}(j)}$. Similarly, Foreign's firms' pricing rules are given by $p_{d k}^{*}(j)=\frac{\left(c_{k}^{*}\right)^{\mu}}{\widetilde{\rho} A_{k}^{*} \varphi_{k}^{*}(j)}$ and $p_{x k}^{*}(j)=\frac{\left(c_{k}^{*}\right)^{\mu} \tau_{x k}^{*}}{\widetilde{\rho} A_{k}^{*} \varphi_{k}^{*}(j)}$. In the rest of the paper, we assume that trade costs are asymmetric, i.e., we allow for the possibility that $\tau_{x k} \neq \tau_{i k} \neq \tau_{x k}^{*} \neq \tau_{i k}^{*}$. In addition to the iceberg trade cost (which is a variable cost), each Home's exporting firm has to bear a fixed cost of exporting, $f_{x}$, which is the same for exporting firms in all sectors, and is incurred in every period.

\footnotetext{
${ }^{5}$ Note that we could allow $\gamma$ and $\sigma$ to be different across sectors and still obtain all the propositions of this paper, but the derivation would be very tedious and no additional insights are obtained.
} 


\subsection{Firm entry and exit}

Cost minimization implies that the gross revenue and net profit of Home's firm $j$ in differentiated sector $k$ from domestic sales are, respectively:

$$
\begin{aligned}
& r_{d k}(j)=\beta_{k} L\left[\frac{p_{d k}(j)}{P_{k}}\right]^{1-\sigma}, \\
& \pi_{d k}(j)=\frac{r_{d k}(j)}{\sigma}-f .
\end{aligned}
$$

The expressions for the corresponding variables for Foreign's firms, $r_{d k}^{*}(j)$ and $\pi_{d k}^{*}(j)$, are defined analogously. Following the same logic, the gross exporting revenue and net exporting profit of Home's firm $j$ in sector $k$ are, respectively:

$$
\begin{aligned}
& r_{x k}(j)=\beta_{k} L^{*}\left[\frac{p_{x k}(j)}{P_{k}^{*}}\right]^{1-\sigma}, \\
& \pi_{x k}(j)=\frac{r_{x k}(j)}{\sigma}-f_{x} .
\end{aligned}
$$

The expressions for the corresponding variables for Foreign's firms, $r_{x k}^{*}(j)$ and $\pi_{x k}^{*}(j)$, are defined analogously.

Hereinafter, "productivity" is synonymous with "total factor productivity" unless otherwise stated. If a firm's productivity is too low, it would not survive after entry, as its expected economic profit is negative. Likewise, a surviving firm would not export if its productivity is so low that its expected economic profits from exporting is negative. Let $\bar{\varphi}_{d k}$ and $\bar{\varphi}_{x k}$ denote the firm-specific components of the productivity cutoffs in sector $k$ for domestic sales (i.e. for survival) and exporting respectively for Home's firms; $\bar{\varphi}_{d k}^{*}$ and $\bar{\varphi}_{x k}^{*}$ denote the corresponding variables for Foreign. It is clear that the mass of exporting firms in Home, $\theta_{x k}$, can be expressed as:

$$
\theta_{x k}=\frac{1-G\left(\bar{\varphi}_{x k}\right)}{1-G\left(\bar{\varphi}_{d k}\right)} \theta_{d k}=\left(\frac{\bar{\varphi}_{d k}}{\bar{\varphi}_{x k}}\right)^{\gamma} \theta_{d k}
$$

where $\theta_{d k}$ denotes the mass of surviving firms in Home, and $G($.$) denotes the cdf of the Pareto dis-$ tribution with shape parameter $\gamma$. The corresponding relationship between the variables $\theta_{x k}^{*}$ and $\theta_{d k}^{*}$ for Foreign can be written analogously. By definition, the mass of varieties available to consumers in differentiated-good sector $k$ in Home is equal to

$$
\theta_{k}=\theta_{d k}+\theta_{x k}^{*}
$$

and $\theta_{k}^{*}$ is defined analogously. The aggregate price indexes of final goods in sector $k$ in Home and Foreign, respectively, are given by:

$$
P_{k}=\left(\theta_{k}\right)^{\frac{1}{1-\sigma}} p_{d k}\left(\widetilde{\varphi}_{k}\right), \quad P_{k}^{*}=\left(\theta_{k}^{*}\right)^{\frac{1}{1-\sigma}} p_{d k}^{*}\left(\widetilde{\varphi}_{k}^{*}\right)
$$

where $\widetilde{\varphi}_{k}$ and $\widetilde{\varphi}_{k}^{*}$ denote the firm-specific component of the aggregate (i.e. average) productivity in

differentiated-good sector $k$ for goods sold in Home and Foreign, respectively; $p_{d k}(\varphi) \equiv \frac{\left(c_{k}\right)^{\mu}}{\widetilde{\rho} A_{k} \varphi}$ and 
$p_{d k}^{*}(\varphi) \equiv \frac{\left(c_{k}^{*}\right)^{\mu}}{\widetilde{\rho} A_{k}^{*} \varphi}$. It is straightforward to show that

$$
\begin{aligned}
& \left(\widetilde{\varphi}_{k}\right)^{\sigma-1}=\frac{1}{\theta_{k}}\left\{\theta_{d k}\left(\widetilde{\varphi}_{d k}\right)^{\sigma-1}+\theta_{x k}^{*}\left[\frac{1}{\tau_{x k}^{*} a_{k}}\left(\frac{c_{k}}{c_{k}^{*}}\right)^{\mu} \widetilde{\varphi}_{x k}^{*}\right]^{\sigma-1}\right\}, \\
& \left(\widetilde{\varphi}_{k}^{*}\right)^{\sigma-1}=\frac{1}{\theta_{k}^{*}}\left\{\theta_{d k}^{*}\left(\widetilde{\varphi}_{d k}^{*}\right)^{\sigma-1}+\theta_{x k}\left[\frac{a_{k}}{\tau_{x k}}\left(\frac{c_{k}^{*}}{c_{k}}\right)^{\mu} \widetilde{\varphi}_{x k}\right]^{\sigma-1}\right\}
\end{aligned}
$$

where $\widetilde{\varphi}_{d k}\left(\widetilde{\varphi}_{d k}^{*}\right)$ and $\widetilde{\varphi}_{x k}\left(\widetilde{\varphi}_{x k}^{*}\right)$ denote respectively the firm-specific component of aggregate productivity level of all of Home's (Foreign's) surviving firms and Home's (Foreign's) exporting firms. ${ }^{6}$ The relationships between $\widetilde{\varphi}_{d k}$ and $\bar{\varphi}_{d k}$, between $\widetilde{\varphi}_{d k}^{*}$ and $\bar{\varphi}_{d k}^{*}$, between $\widetilde{\varphi}_{x k}$ and $\bar{\varphi}_{x k}$, and between $\widetilde{\varphi}_{x k}^{*}$ and $\bar{\varphi}_{x k}^{*}$, are given by

$$
\widetilde{\varphi}_{s k}=\left(\frac{\gamma}{\gamma-\sigma+1}\right)^{\frac{1}{\sigma-1}} \bar{\varphi}_{s k} \quad \text { and } \quad \widetilde{\varphi}_{s k}^{*}=\left(\frac{\gamma}{\gamma-\sigma+1}\right)^{\frac{1}{\sigma-1}} \bar{\varphi}_{s k}^{*} \quad \text { for } \quad s=x, d .
$$

From the above equations, it is obvious that these aggregate productivity measures as well as aggregate price indexes are functions of $\left(\bar{\varphi}_{d k}, \bar{\varphi}_{d k}^{*}, \bar{\varphi}_{x k}, \bar{\varphi}_{x k}^{*}, \theta_{d k}, \theta_{d k}^{*}\right)$. As will be shown below, as long as $\frac{f_{x}}{f}$ is sufficiently large, then for each sector, only a fraction of surviving firms will export. In that case, an entering firm will produce only if it can generate positive expected profit by selling domestically, and export only if it can generate positive expected profit by selling abroad. ${ }^{7}$ The zero cutoff profit (ZCP) condition dictates that the marginal surviving firm makes zero post-entry expected economic profits. Thus we obtain four ZCP conditions, which are relegated to the appendix. Suppose $\tilde{\pi}_{k}$ and $\tilde{\pi}_{k}^{*}$ denote the average profit flow of a surviving firm in sector $k$ in Home and Foreign respectively. A firm will enter if its expected post-entry profit is above the fixed cost of entry. The free entry (FE) condition determines that the entry cost is equal to the post-entry expected economic profits. Hence, the FE conditions for Home and Foreign are, respectively $f_{e}=\left[1-G\left(\bar{\varphi}_{d k}\right)\right] \tilde{\pi}_{k}$ and $f_{e}=\left[1-G\left(\bar{\varphi}_{d k}^{*}\right)\right] \tilde{\pi}_{k}^{*}$. These equations can be expressed in terms of $\bar{\varphi}_{d k}, \bar{\varphi}_{x k}, \bar{\varphi}_{d k}^{*}$, and $\bar{\varphi}_{x k}^{*}$ owing to the ZCP conditions. They are relegated to the appendix.

\subsection{General equilibrium}

\section{Two-way trade sectors}

Assuming that both countries produce in sector $k$, given the wage ratio $A_{h} / A_{h}^{*}=1$, we can solve for $\left(\bar{\varphi}_{d k}, \bar{\varphi}_{d k}^{*}, \bar{\varphi}_{x k}, \bar{\varphi}_{x k}^{*}, \theta_{d k}, \theta_{d k}^{*}\right)$ from the four zero cutoff profit conditions and two free entry conditions (15) to (20) since the aggregate prices are functions of these six variables. (For details, please refer to Appendix A). The solutions are given below. Define $D_{1} \equiv\left(\frac{\sigma-1}{\gamma-\sigma+1}\right) \frac{f}{f_{e}}$ and $D_{2}(k) \equiv\left(\frac{\gamma-\sigma+1}{\gamma}\right) \frac{\beta_{k}}{\sigma f}$.

\footnotetext{
${ }^{6}$ The derivation of the above two equations are available from the corresponding author's homepage at http://ihome.ust.hk/ elai/ or upon request.

${ }^{7}$ The condition is $\frac{f_{x}}{f}>\max \left\{\frac{L}{L^{*}}, \frac{L^{*}}{L}\right\}$. If this condition is not satisfied, then there exist some sectors in which all firms export (besides serving the domestic market).
} 


$$
\begin{aligned}
& \left(\bar{\varphi}_{d k}\right)^{\gamma}=D_{1}\left[\frac{B_{1 k}-B_{2 k}^{-1}}{B_{1 k}-B_{3 k}\left(a_{k}\right)^{\gamma}}\right] \\
& \left(\bar{\varphi}_{d k}^{*}\right)^{\gamma}=D_{1}\left[\frac{B_{2 k}-B_{1 k}^{-1}}{B_{2 k}-B_{3 k}^{-1}\left(a_{k}\right)^{-\gamma}}\right] \\
& \bar{\varphi}_{x k}=\left(\frac{B_{1 k} f_{x}}{B_{3 k} f}\right)^{\frac{1}{\gamma}} \frac{\bar{\varphi}_{d k}^{*}}{a_{k}} \\
& \bar{\varphi}_{x k}^{*}=\left(\frac{B_{2 k} B_{3 k} f_{x}}{f}\right)^{\frac{1}{\gamma}} a_{k} \bar{\varphi}_{d k} \\
& \theta_{d k}=D_{2}(k)\left[\frac{B_{1 k} L-\frac{B_{1 k}-B_{3 k}\left(a_{k}\right)^{\gamma}}{B_{2 k} B_{3 k}\left(a_{k}\right)^{\gamma}-1} L^{*}}{B_{1 k}-B_{2 k}^{-1}}\right] \\
& \theta_{d k}^{*}=D_{2}(k)\left[\frac{B_{2 k} L^{*}-\frac{B_{2 k} B_{3 k}\left(a_{k}\right)^{\gamma}-1}{B_{1 k}-B_{3 k}\left(a_{k}\right)^{\gamma}} L}{B_{2 k}-B_{1 k}^{-1}}\right]
\end{aligned}
$$

where $B_{1 k} \equiv\left(\tau_{x k}\right)^{\gamma}\left(\frac{f_{x}}{f}\right)^{\frac{\gamma}{\sigma-1}-1} ; B_{2 k} \equiv\left(\tau_{x k}^{*}\right)^{\gamma}\left(\frac{f_{x}}{f}\right)^{\frac{\gamma}{\sigma-1}-1} ; B_{3 k} \equiv\left[\frac{T^{*}+T \cdot\left(\tau_{i k}^{*}\right)^{-\lambda}}{T+T^{*} \cdot\left(\tau_{i k}\right)^{-\lambda}}\right]^{-\mu \gamma / \lambda}$. The variables $B_{1 k}$ and $B_{2 k}$ can be interpreted as summary measures of export trade barriers in sector $k ; B_{3 k}$ reflects the relative cost of intermediate goods; $a_{k}$ can be interpreted as the relative competitiveness of Home in differentiated-good sector $k$. Recall that $a^{\prime}(k)>0$ is assumed.

In a one-sector model, Melitz (2003) imposes the condition $\tau^{\sigma-1} f_{x}>f$ so as to ensure that some firms produce exclusively for their domestic market in both countries. In this paper, we adopt a more stringent condition, $\frac{f_{x}}{f}>\max \left\{\frac{L}{L^{*}}, \frac{L^{*}}{L}\right\}$, so as to ensure that, in each country, some firms sell exclusively to their domestic market in all sectors. ${ }^{8}$ This condition implies that $B_{1 k}$ and $B_{2 k}$ are both larger than one. 9

Home's firms will exit sector $k$ when $\theta_{d k} \leq 0$, and Foreign's firms will exit the sector if $\theta_{d k}^{*} \leq 0$. From equations (9) and (10), this implies that $B_{1 k}^{-1}\left[\frac{B_{1 k}-B_{3 k}\left(a_{k}\right)^{\gamma}}{B_{2 k} B_{3 k}\left(a_{k}\right)^{\gamma}-1}\right]<\frac{L}{L^{*}}<B_{2 k}\left[\frac{B_{1 k}-B_{3 k}\left(a_{k}\right)^{\gamma}}{B_{2 k} B_{3 k}\left(a_{k}\right)^{\gamma}-1}\right]$ is needed for both countries to produce positive outputs in sector $k$, otherwise there will be complete dominance by one country in the sector and one-way trade. Rearranging these inequalities, we can sort the sectors into three types according to Home's strength of comparative advantage.

\section{One-way trade sectors}

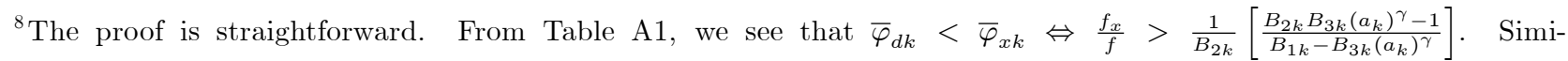
larly, $\bar{\varphi}_{d k}^{*}<\bar{\varphi}_{x k}^{*} \Leftrightarrow \frac{f_{x}}{f}>\frac{1}{B_{1 k}}\left[\frac{B_{1 k}-B_{3 k}\left(a_{k}\right)^{\gamma}}{B_{2 k} B_{3 k}\left(a_{k}\right)^{\gamma}-1}\right]$. Equations (9) and (10) imply that $\frac{1}{B_{2 k}}\left[\frac{B_{2 k} B_{3 k}\left(a_{k}\right)^{\gamma}-1}{B_{1 k}-B_{3 k}\left(a_{k}\right)^{\gamma}}\right] \leq \frac{L^{*}}{L}$ and $\frac{1}{B_{1 k}}\left[\frac{B_{1 k}-B_{3 k}\left(a_{k}\right)^{\gamma}}{B_{2 k} B_{3 k}\left(a_{k}\right)^{\gamma}-1}\right] \leq \frac{L}{L^{*}}$ for $k \in\left[k_{1}, k_{2}\right]$, where $\theta_{d k} \geq 0$ and $\theta_{d k}^{*} \geq 0$. Hence $\frac{f_{x}}{f}>\max \left\{\frac{L}{L^{*}}, \frac{L^{*}}{L}\right\}$ is a sufficient condition for $\bar{\varphi}_{d k}<\bar{\varphi}_{x k}$ and $\bar{\varphi}_{d k}^{*}<\bar{\varphi}_{x k}^{*}$ for all two-way trade sectors.

In addition, Table A1 shows that $\frac{f_{x}}{f}>\max \left\{\frac{L}{L^{*}}, \frac{L^{*}}{L}\right\}$ is also a sufficient condition for $\bar{\varphi}_{d k}<\bar{\varphi}_{x k}$ and $\bar{\varphi}_{d k}^{*}<\bar{\varphi}_{x k}^{*}$ (whenever the country produces) for all one-way trade sectors.

${ }^{9}$ As $\tau>1, \frac{f_{x}}{f} \geq 1$, and $\gamma>\sigma-1$, it is obvious that $B_{1}$ and $B_{2}$ are both larger than one under our condition.
} 
In sector $k$, Home will not produce iff $a_{k} \leq a_{k 1}$, where

$$
\left(a_{k 1}\right)^{\gamma}=\frac{1}{B_{3 k}}\left[\frac{B_{1 k}\left(\frac{L}{L^{*}}+1\right)}{B_{1 k} B_{2 k} \frac{L}{L^{*}}+1}\right] ;
$$

and Foreign will not produce in sector $k$ iff $a_{k} \geq a_{k_{2}}$, where ${ }^{10}$

$$
\left(a_{k 2}\right)^{\gamma}=\frac{1}{B_{3 k}}\left[\frac{B_{1 k} B_{2 k} \frac{L^{*}}{L}+1}{B_{2 k}\left(\frac{L^{*}}{L}+1\right)}\right] .
$$

Therefore, the solutions to (5)-(10) are valid if and only if $a_{k} \in\left(a_{k 1}, a_{k 2}\right)$. It is clear that $\left(a_{k}\right)^{\gamma} \in$ $\left(\frac{1}{B_{3 k} B_{2 k}}, \frac{B_{1 k}}{B_{3 k}}\right)$ for any possible GDP ratio $L / L^{*}$, which ensures that the productivity cutoffs will never reach the corner for the sectors in which both countries produce.

When $a_{k} \notin\left(a_{k 1}, a_{k 2}\right)$, the number of surviving firms in one of the countries solved from the system (5)-(10) is negative. In that case, there is no interior solution to some of the equations in the system. This reflects the fact that no firm from that country enters in sector $k$, which means that the other country completely dominates that sector. Therefore, a different set of equations need to be solved for this case. Without loss of generality, we consider the Home-dominated sectors. Because only Home's firms sell in each country, the aggregate price indexes become

$$
\begin{aligned}
& P_{k}=\left(\theta_{d k}\right)^{\frac{1}{1-\sigma}} \frac{\left(c_{k}\right)^{\mu}}{\widetilde{\rho} A_{k} \widetilde{\varphi}_{d k}} \\
& P_{k}^{*}=\left(\theta_{x k}\right)^{\frac{1}{1-\sigma}} \frac{\tau_{x k}\left(c_{k}\right)^{\mu}}{\widetilde{\rho} A_{k} \widetilde{\varphi}_{x k}}
\end{aligned}
$$

Nonetheless, the two zero cutoff profit conditions for Home, (15) and (17), continue to hold.

Moreover, the free entry condition (19) for Home's firms continues to hold. Thus, solving the diminished system of three equations (15), (17), (19) for three unknowns, we have

$$
\begin{aligned}
\theta_{d k} & =\frac{\beta_{k} L}{\sigma f}\left(\frac{\gamma-\sigma+1}{\gamma}\right)=D_{2}(k) L \\
\theta_{x k} & =\frac{\beta_{k} L^{*}}{\sigma f_{x}}\left(\frac{\gamma-\sigma+1}{\gamma}\right)=D_{2}(k) \frac{f}{f_{x}} L^{*} \\
\left(\bar{\varphi}_{d k}\right)^{\gamma} & =\frac{L+L^{*}}{L} D_{1} .
\end{aligned}
$$

Furthermore, we can easily obtain $\left(\bar{\varphi}_{x k}\right)^{\gamma}=\left(\frac{L+L^{*}}{L^{*}}\right) \frac{f_{x}}{f} D_{1}$ by noting that $\theta_{x k}=\frac{1-G\left(\bar{\varphi}_{x k}\right)}{1-G\left(\bar{\varphi}_{d k}\right)} \theta_{d k}$. An analogous set of solutions for the Foreign-dominated sectors can be obtained. ${ }^{11},{ }^{12}$ When $\tau_{x k}, \tau_{i k}, \tau_{x k}^{*}$ and $\tau_{i k}^{*}$ are equal across sectors, we have the following proposition

Proposition 1 When $a_{k} \geq a_{k 2}\left(a_{k} \leq a_{k 1}\right)$, only Home (Foreign) produces in sector $k$, and there is one-way trade. When $a_{k} \in\left(a_{k 1}, a_{k 2}\right)$, both countries produce in sector $k$, and there is two-way trade.

\footnotetext{
${ }^{10}$ Because $\frac{B_{1 k} B_{2 k} \frac{L^{*}}{L}+1}{B_{2 k}\left(\frac{L^{*}}{L}+1\right)}>\frac{B_{1 k}\left(\frac{L}{L^{*}}+1\right)}{B_{1 k} B_{2 k} \frac{L}{L^{*}}+1}$ holds, we always have $a_{k_{1}}<a_{k_{2}}$.

${ }^{11}$ They are: $\theta_{d k}^{*}=\frac{\beta_{k} L^{*}}{\sigma f}\left(\frac{\gamma-\sigma+1}{\gamma}\right)=D_{2}(k) L^{*} ; \theta_{x k}^{*}=\frac{\beta_{k} L}{\sigma f_{x}}\left(\frac{\gamma-\sigma+1}{\gamma}\right)=D_{2}(k) \frac{f}{f_{x}} L ;$ and $\left(\bar{\varphi}_{d k}^{*}\right)^{\gamma}=\frac{L+L^{*}}{L^{*}} D_{1}$.

${ }^{12}$ The uniqueness of the above equilibrium is proved in an appendix posted on the corresponding author's homepage at http://ihome.ust.hk/ elai/ or upon request.
} 
Assuming that $a^{\prime}(k)>0$, that $\tau_{x k}, \tau_{i k}, \tau_{x k}^{*}, \tau_{i k}^{*}$ and $\beta_{k}$ are equal across sectors, and that $L<$ $L^{*}$, we obtain three zones of international specialization as shown in Figure 1. The upward sloping curve (including the dotted portions) corresponds to equation (9), while the downward sloping curve (including the dotted portions) corresponds to equation (10). The horizontal portion of $\theta_{d k}$ in the diagram corresponds to the equation for $\theta_{d k}$ above when Home dominates sector $k$ completely. The horizontal portion of $\theta_{d k}^{*}$ corresponds to the analogous equation for Foreign.

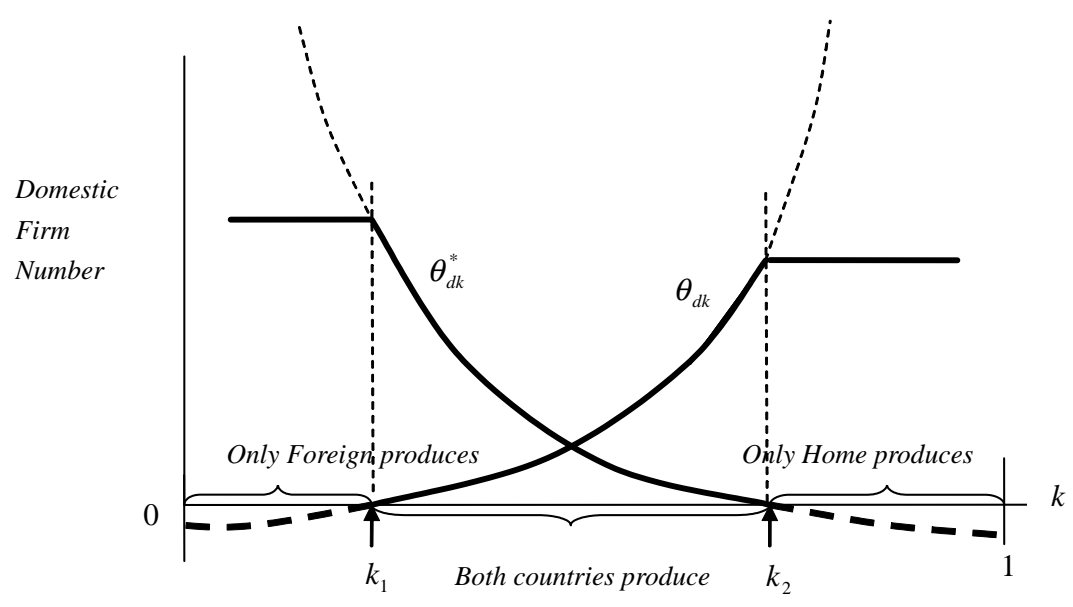

Figure 1. Three Zones of International Specialization (assumption: (i) $a_{k}$

increases in $k$, (ii) tariffs on imported-inputs, imported-outputs, exported-inputs and exported-outputs and expenditure shares $\beta_{k}$ are equal across sectors; (iii) $L<L^{*}$ ).

We list the solutions to the relevant variables corresponding to the three types of sectors in Table A1 in the appendix for easy reference.

\section{Trade liberalization}

China's trade liberalization following her accession to the World Trade Organization (WTO) has been widely recognized as primarily unilateral liberalization. It also provides a natural experiment for us to evaluate the impacts of exogenous tariff reduction (Fan, et al. 2015). Chinese customs data also show that a vast majority of Chinese imports were intermediate goods rather than final goods at the time of the WTO-induced trade liberalization in China in 2001 (Fan, et al. 2015). Refer to Figure A1 in the appendix. This justifies the focus of our empirical analysis on the effects of unilateral imported-input trade liberalization. 
According to our theory, in the one-way trade sectors, the productivity cutoff for survival and productivity cutoff for exporting are independent of $\tau_{x k}, \tau_{i k}, \tau_{x k}^{*}$ and $\tau_{i k}^{*}$, which means that trade liberalization has no effect on firm production and exporting behavior. We do not believe this describe the behavior of the firms in our data. Therefore, we only focus on the two-way trade sectors.

\subsection{Imported-input trade liberalization}

According to equations (5) and (7), the effects of trade liberalization in imported inputs on the productivity cutoff for survival, $\bar{\varphi}_{d k}$, and productivity cutoff for exporting, $\bar{\varphi}_{x k}$, are given by

$$
\begin{aligned}
& \frac{d \ln \left(\bar{\varphi}_{d k}\right)}{d \tau_{i k}}=-\left[\frac{B_{3 k}\left(a_{k}\right)^{\gamma}}{B_{1 k}-B_{3 k}\left(a_{k}\right)^{\gamma}}\right] \frac{\mu T^{*}\left(\tau_{i k}\right)^{-\lambda-1}}{T+T^{*}\left(\tau_{i k}\right)^{-\lambda}}<0 \\
& \frac{d \ln \left(\bar{\varphi}_{x k}\right)}{d \tau_{i k}}=\left[\frac{B_{2 k}}{B_{2 k}-B_{3 k}^{-1}\left(a_{k}\right)^{-\gamma}}\right] \frac{\mu T^{*}\left(\tau_{i k}\right)^{-\lambda-1}}{T+T^{*}\left(\tau_{i k}\right)^{-\lambda}}>0
\end{aligned}
$$

That is, trade liberalization in imported inputs (a reduction of $\tau_{i k}$ ) leads to a rise in $\bar{\varphi}_{d k}$ and a fall in $\bar{\varphi}_{x k}$.

Moreover, the fraction of exporting firms in sector $k$ is given by $\frac{\theta_{x k}}{\theta_{d k}}=\left(\frac{\bar{\varphi}_{d k}}{\bar{\varphi}_{x k}}\right)^{\gamma}=\frac{f}{f_{x}}\left[\frac{B_{3 k}\left(a_{k}\right)^{\gamma}-B_{2 k}^{-1}}{B_{1 k}-B_{3 k}\left(a_{k}\right)^{\gamma}}\right]$. Therefore, the effect of trade liberalization in imported inputs on the fraction of exporting firms in sector $k$ is given by

$$
\frac{d\left[\frac{\theta_{x k}}{\theta_{d k}}\right]}{d \tau_{i k}}=\frac{d\left[\left(\frac{\bar{\varphi}_{d k}}{\bar{\varphi}_{x k}}\right)^{\gamma}\right]}{d \tau_{i k}}=-\frac{f}{f_{x}}\left[\frac{\left(B_{1 k}-B_{2 k}^{-1}\right) B_{3 k}\left(a_{k}\right)^{\gamma}}{\left[B_{1 k}-B_{3 k}\left(a_{k}\right)^{\gamma}\right]^{2}}\right] \frac{\mu \gamma T^{*}\left(\tau_{i k}\right)^{-\lambda-1}}{T+T^{*}\left(\tau_{i k}\right)^{-\lambda}}
$$

which is negative and decreases with $B_{3 k}\left(a_{k}\right)^{\gamma}$. Thus, trade liberalization in imported inputs leads to an increase in the fraction of exporting firms in all sectors, with the effect stronger in a sector with larger $B_{3 k}\left(a_{k}\right)^{\gamma}$.

We summarize the above results in the following proposition.

Proposition 2 Consider the sectors in which both countries produce. Following trade liberalization in imported intermediate inputs, the productivity cutoff for survival, $\bar{\varphi}_{d k}$, increases and productivity cutoff for exporting, $\bar{\varphi}_{x k}$, decreases in these sectors. Thus the fraction of firms that export increases in all sectors; moreover, the effect is stronger in a sector with higher $B_{3 k}\left(a_{k}\right)^{\gamma}$.

The intuition of the above proposition can be understood more clearly by decomposing the total effect of unilateral trade liberalization in imported inputs into two effects: the inter-sectoral resource allocation (IRA) effect and the Melitz selection effect. We shall analyze from the perspective of Home and Home's firms, and we only focus on the two-way trade sectors.

1. The inter-sectoral resource allocation (IRA) effect (leading to $\bar{\varphi}_{d k} \uparrow$ and $\bar{\varphi}_{x k} \downarrow$ with the change in $\left(\bar{\varphi}_{d k} / \bar{\varphi}_{x k}\right)^{\gamma}$ larger the stronger is the comparative advantage of the sector). Trade liberalization in imported intermediate inputs leads to resources in Home being re-allocated away from the 
homogeneous good sector to the differentiated-good sectors. Moreover, there is more inward allocation of resources, the stronger is the comparative advantage of the sector. The IRA effect tends to raise the aggregate productivity in all sectors, but the stronger is the comparative advantage of a sector, the stronger is the effect. Define $n_{k}$ and $n_{k}^{*}$ as the mass of entrants in sector $k$ in Home and Foreign respectively. ${ }^{13}$ Note that $\theta_{d k}=n_{k}\left[1-G\left(\bar{\varphi}_{d k}\right)\right]$. Re-allocation of resource (labor) from the homogeneous good sector to the differentiated-good sectors explains why, in all sectors, the mass of Home's entrants $\left(n_{k}\right)$ increases, while the mass of Foreign's entrants $\left(n_{k}^{*}\right)$ decreases. As $n_{k}^{*}$ decreases, Foreign's market becomes less competitive (as there are fewer firms in Foreign) and so $r_{x k}(\varphi)$ increases for all $\varphi$. This creates pressure for a decrease in $\bar{\varphi}_{x k}$ (i.e. the Home firms which were marginally unprofitable in exporting before now become profitable in exporting). As $n_{k}$ increases, $\theta_{d k}$ also increases. This leads to the shrinking of the sizes of the surviving Home firms. Thus, $r_{d k}(\varphi)$ decreases for all $\varphi$. This creates pressure for an increase in $\bar{\varphi}_{d k}$ as some less productive firms which were expected to be marginally profitable before can be expected to be unprofitable now. In other words, the exporting firms in Home, which are most productive, would expand, and so they compete away resources from the less productive, non-exporting, firms. The previously least productive surviving firms in Home would exit, and the marginal firm that were profitable before now becomes unprofitable. Note that this IRA effect is stronger, the stronger is the comparative advantage of a sector. In a sector with stronger comparative advantage, $n_{k}$ increases more and $n_{k}^{*}$ decreases more; moreover, more resources are re-allocated towards the sector and the reallocation favors the exporting firms compared to the non-exporters as a result of the less competitive foreign market. Consequently, the increase in the fraction of firms that export is larger in a sector with stronger comparative advantage.

2. The Melitz selection effect (within-sector resource allocation effect) - leading to $\bar{\varphi}_{d k} \uparrow$ and $\bar{\varphi}_{x k} \downarrow$ in all sectors equally. As $\tau_{i k}$ falls (i.e. $B_{3 k}$ rises), it raises the aggregate productivity of Home in all sectors. In this analysis, we ignore the IRA effect, i.e. suppose that the masses of entrants $n_{k}$ and $n_{k}^{*}$ were to remain fixed. In other words, the expected toughness of competition for an exporting firm from Home is unchanged. As a result, the export revenue of a typical exporting firm in Home will increase as a reduction in tariff on imported inputs increases the competitiveness of Home's firms in Foreign. This creates pressure for $\bar{\varphi}_{x k}$ to decrease. The exporting firms in Home, which are most productive, would expand, bidding up Home's wage, and compete away resources from the less productive, nonexporting, firms. This will force the least productive firms in Home to exit. This creates pressure for $\bar{\varphi}_{d k}$ to increase. This is the Melitz selection effect. Its magnitude is independent of the strength of comparative advantage of a sector.

3. The IRA effect reinforces the Melitz selection effect. The interaction of the last two forces reinforce each other following trade liberalization in imported inputs. The existence of IRA effect causes the total effect to differ across sectors. The reallocation of resources to the exporting firms relative to non-exporters is stronger, the stronger is the initial comparative advantage of a sector.

\footnotetext{
${ }^{13}$ The domestic mass of entrants satisfies: $n_{k}=\theta_{d k}\left(\bar{\varphi}_{d k}\right)^{\gamma}=D_{1} D_{2}\left[\frac{B_{1 k}}{B_{1 k}-B_{3 k}\left(a_{k}\right)^{\gamma}} L-\frac{1}{B_{2 k} B_{3 k}\left(a_{k}\right)^{\gamma}-1} L^{*}\right]$, The foreign mass of entrants satisfies: $n_{k}^{*}=\theta_{d k}^{*}\left(\bar{\varphi}_{d k}^{*}\right)^{\gamma}=D_{1} D_{2}\left[\frac{B_{2 k}}{B_{2 k}-B_{3 k}^{-1}\left(a_{k}\right)^{-\gamma}} L^{*}-\frac{1}{B_{1 k} B_{3 k}^{-1}\left(a_{k}\right)^{-\gamma}-1} L\right]$.
} 
Note that comparative advantage should be measured by $B_{3 k} a_{k}^{\gamma}$, which reflects the sector-specific (as opposed to firm-specific) component of relative productivity. It is composed of two parts: $a_{k} \equiv \frac{A_{k}}{A_{k}^{*}}$, which reflects the sector-specific component of relative productivity and $B_{3 k} \equiv\left[\frac{T^{*}+T\left(\tau_{i k}^{*}\right)^{-\lambda}}{T+T^{*}\left(\tau_{i k}\right)^{-\lambda}}\right]^{-\mu \gamma / \lambda}$, which represents the relative cost of intermediate inputs.

The change in the fraction of firms that export is not the only interesting effect of imported-input trade liberalization on export performance. We have derived two more testable hypotheses as described below. They are intimately related to how $\left(\frac{\bar{\varphi}_{d k}}{\bar{\varphi}_{x k}}\right)^{\gamma}$ is affected by the reduction of $\tau_{i k}$. Thus, the signs of the derivatives are the same. Their proofs are given in the appendix.

Proposition 3 Consider the sectors in which both countries produce. Following trade liberalization in imported inputs, the probability of entry into the export market for a previously non-exporting firm is higher in a sector with higher $B_{3 k} a_{k}^{\gamma}$.

Proposition 4 Consider the sectors in which both countries produce. Following trade liberalization in imported inputs, the change in the revenue share from exporting is larger in a sector with higher $B_{3 k} a_{k}^{\gamma}$.

\subsection{Reduction of tariffs on exported-outputs, exported-inputs and imported-outputs}

Compared with imported-input trade liberalization, how do trade liberalization in exported final goods $\left(\tau_{x k} \downarrow\right)$, exported intermediate goods $\left(\tau_{i k}^{*} \downarrow\right)$ and imported final goods $\left(\tau_{x k}^{*} \downarrow\right)$ affect the productivity cutoffs for survival and exporting, and the fraction of firms that export? From equations (5) and (7), the effect of trade liberalization in exported final goods, exported intermediate goods and imported final goods on $\bar{\varphi}_{d k}, \bar{\varphi}_{x k}$ and $\left(\frac{\bar{\varphi}_{d k}}{\bar{\varphi}_{x k}}\right)^{\gamma}$ in the two-way trade sectors can be easily calculated. As before, the effects on $\left(\frac{\bar{\varphi}_{d k}}{\bar{\varphi}_{x k}}\right)^{\gamma}$ are intimately related to how the three export performance variables stated in the last three propositions are affected by reduction of tariffs. The detailed expressions for the derivatives are relegated to the appendix. Here we just state the signs of the derivatives below.

$$
\begin{aligned}
& \frac{d \ln \left(\bar{\varphi}_{d k}\right)}{d \tau_{x k}}<0 ; \frac{d \ln \left(\bar{\varphi}_{d k}\right)}{d \tau_{i k}^{*}}>0 ; \frac{d \ln \left(\bar{\varphi}_{d k}\right)}{d \tau_{x k}^{*}}>0 \\
& \frac{d \ln \left(\bar{\varphi}_{x k}\right)}{d \tau_{x k}}>0 ; \frac{d \ln \left(\bar{\varphi}_{x k}\right)}{d \tau_{i k}^{*}}<0 ; \frac{d \ln \left(\bar{\varphi}_{x k}\right)}{d \tau_{x k}^{*}}<0 \\
& \frac{d\left(\frac{\bar{\varphi}_{d k}}{\bar{\varphi}_{x k}}\right)^{\gamma}}{d \tau_{x k}}<0 ; \frac{d\left(\frac{\bar{\varphi}_{d k}}{\bar{\varphi}_{x k}}\right)^{\gamma}}{d \tau_{i k}^{*}}>0 ; \frac{d\left(\frac{\bar{\varphi}_{d k}}{\bar{\varphi}_{x k}}\right)^{\gamma}}{d \tau_{x k}^{*}}>0
\end{aligned}
$$

In each case in the last line, the magnitude of the effect on $\left(\frac{\bar{\varphi}_{d k}}{\bar{\varphi}_{x k}}\right)^{\gamma}$ is larger, the larger is $B_{3 k}\left(a_{k}\right)^{\gamma}$.

The effects of trade liberalization in exported final goods are similar to those for imported intermediate goods. Both effects raise the productivity cutoff for survival, $\bar{\varphi}_{d k}$, and lower the cutoff for exporting, $\bar{\varphi}_{x k}$; moreover, the fraction of firms that export increases and the effect is larger in a sector with higher $B_{3 k}\left(a_{k}\right)^{\gamma}$. However, the effects of trade liberalization in exported 
intermediate goods and imported final goods are different. They would lower the productivity cutoff for survival and raise the cutoff for exporting. This is because trade liberalization in exported intermediate goods and imported final goods increases Foreign's firms competitiveness in Home's market and hence $r_{x k}^{*}(\varphi)$ increases for all $\varphi$. This induces more firms to enter in Foreign (i.e. $n_{k}^{*}$ increases) and raises the competitiveness of Foreign's market. As a result, Home firm's export revenue $r_{x k}(\varphi)$ falls for all $\varphi$, which creates pressure for a increase in $\bar{\varphi}_{x k}$. As the exporting firms are the most productive ones, their contraction bids down Home's wage, which allows the less productive firms to expand. Thus, $r_{d k}(\varphi)$ increases for all $\varphi$. The previously unprofitable marginal firm now becomes profitable. This creates pressure for a decrease in $\bar{\varphi}_{d k}$. Thus the trade liberalization in exported intermediate goods or imported final goods lowers the fraction of exporting firms in sector $k$. The magnitudes of the effects are also larger in a sector with higher $B_{3 k}\left(a_{k}\right)^{\gamma}$.

\section{Empirical Specification, Data and Measurement}

In this section, we specify our econometric models and describe the data and measurements of the main variables that are used in the estimation.

\subsection{Estimating Equations}

To examine proposition 3 , we estimate the impact on the probability of entry into the export market using logistic regressions. Based on our theory, the probability of entry into the exporting market for previously non-exporting firms in industry $k$ between year $t$ and year $t+1$ can be written as:

$$
\begin{aligned}
& \operatorname{Pr}\left(\operatorname{Export}_{f, t+1}=1 \mid \operatorname{Export}_{f, t}=0\right) \\
& \quad=\Phi\left(\beta_{1} \Delta \text { duty }_{i k, t}+\beta_{2} \Delta \text { duty }_{i k, t} \times \mathrm{RCA}_{k, t}+\beta_{3} \Delta \text { duty }_{o k, t}+\beta_{4} \mathrm{RCA}_{k, t}+\lambda \mathrm{X}_{f, t}+\delta_{s}+\delta_{t}\right),
\end{aligned}
$$

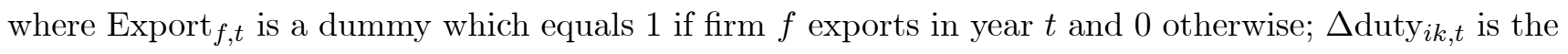
change in the tariff on imported intermediate goods (imported-input tariff) in the 4-digit CIC industry $k$ to which firm $f$ belongs, between year $t$ and year $t+1 ; \mathrm{RCA}_{k, t}$ is the revealed comparative advantage of the 4-digit CIC industry $k$ in year $t ; \Delta$ duty $_{i k, t} \times \mathrm{RCA}_{k, t}$ is an interactive term of the change in importedinput tariff and the revealed comparative advantage of industry $k ; \Delta$ duty $_{o k, t}$ is the change in the tariff of imported final goods (i.e. imported-output tariff) of the 4-digit CIC industry $k$ between year $t$ and year $t+1 ; \mathrm{X}_{f, t}$ is a vector of firm characteristics of firm $f$ in year $t$ including firm productivity, labor employment, capital-labor ratio and the wage per worker, $\delta_{s}$ is a set of 2-digit CIC industry dummies to control for the unobserved heterogeneity and $\delta_{t}$ is a set of time dummies.

We will test propositions 2 and 4 according to the following two equations respectively:

$$
\begin{aligned}
& \Delta\left(\frac{\theta_{x k, t}}{\theta_{d k, t}}\right)=\gamma_{1} \Delta \text { duty }_{i k, t}+\gamma_{2} \Delta \text { duty }_{i k, t} \times \mathrm{RCA}_{k, t}+\gamma_{3} \Delta \text { duty }_{o k, t}+\gamma_{4} \mathrm{RCA}_{k, t}+\mu \mathrm{X}_{k, t}+\delta_{s}+\delta_{t}+\varepsilon_{i t} \\
& \Delta\left(\frac{V_{x k, t}}{V_{k, t}}\right)=\delta_{1} \Delta \text { duty }_{i k, t}+\delta_{2} \Delta \text { duty }_{i k, t} \times \mathrm{RCA}_{k, t}+\delta_{3} \Delta \mathrm{duty}_{o k, t}+\delta_{4} \mathrm{RCA}_{k, t}+\nu \mathrm{X}_{k, t}+\delta_{s}+\delta_{t}+\eta_{i t}
\end{aligned}
$$


where $\theta_{x k, t}$ and $\theta_{d k, t}$ denote respectively the number of exporting firm and the total number of producing firms in industry $k$ in year $t ; V_{x k, t}$ and $V_{k, t}$ respectively represent the exporting revenue and the total revenue in industry $k$ at time $t ; \Delta$ denotes the change of a variable from year $t$ to year $t+1 ; \mathrm{X}_{k, t}$ is a vector of industry characteristics including the firm-revenue-weighted average TFP, labor employment, capital-labor ratio and the wage per worker in industry $k ; \delta_{s}$ is a set of CIC 2-digit industry dummies and $\delta_{t}$ is a set of the time dummies.

\subsection{Firm-level Data and Firm-product-level Trade Data}

In the empirical test, we use data extracted from four sources. First, firm-level data are from the National Bureau of Statistics of China (NBSC). Second, firm-product-level import and export data are obtained from China's General Administration of Customs. Third, the import tariffs data are obtained from the WTO website, available as MFN (most-favored nation) tariffs at the HS 8-digit level from the year 2001 to $2006 .{ }^{14}$ Finally, we obtain trade flows data from CEPII, which is used to measure revealed comparative advantage.

The first two data sources deserve more explanation. The firm-level production data covers all stateowned enterprises (SOEs), and non-state-owned enterprises with annual sales of at least 5 million RMB (Chinese currency). ${ }^{15}$ This database has been widely used by previous studies of Chinese economy (e.g., Cai and Liu (2009), Feenstra, Li and Yu (2014), Brandt, Biesebroeck and Zhang (2012), among others) as it contains detailed firm-level information of manufacturing enterprises in China, such as ownership structure, employment, capital stock, gross output, value-added, and complete information on the three major accounting statements (i.e., balance sheets, profit \& loss accounts, and cash flow statements). Of all the information in the NBSC Database, we are mostly interested in the variables related to the measures of the dependent variables which we are interested in (the probability of entry into the foreign market, the fraction of exporting firms and the export revenue share) and firm characteristics. As there are some reporting errors in the NBSC Database, we clean it by following Cai and Liu (2009), Fan, Li and Yeaple (2015) and the Generally Accepted Accounting Principles, and discard observations for which one of the following criteria is violated: (i) the total assets must be higher than the liquid assets; (ii) the total assets must be larger than the total fixed assets; (iii) the total assets must be larger than the net value of the fixed assets; (iv) a firm's identification number cannot be missing and must be unique; and (v) the time of establishment must be valid. In addition, we also discard the observations if firms change the industry they belong to. ${ }^{16}$

China's General Administration of Customs provides us with the universe of all Chinese trade transactions by importing and by exporting firm at the HS 8-digit level for the years 2001-2006. Each trade transaction includes import and export values, quantities, products, source and destination countries, customs regime (e.g. "Processing and Assembling" and "Processing with Imported Materials"), type of

\footnotetext{
${ }^{14}$ The tariff data are available at http://tariffdata.wto.org/ReportersAndProducts.aspx.

${ }^{15}$ It equals US $\$ 640,000$ approximately, according to the official end-of-period exchange rate in 2006, reported by the central bank of China.

${ }^{16}$ Discarding the observations if firms change industry they belong to would not affect our results.
} 
enterprise (e.g. state-owned, domestic private firm, foreign-invested, and joint ventures), and contact information for the firm (e.g. company name, phone number, zip code, contact person). We aggregate the trade data to firm-product-year level. In order to calculate the imported intermediate-good tariff and imported final-good tariff in each industry, we need to use the contact information of manufacturing firms to match the firm-product level trade data from the Chinese Customs Database to the NBSC Database. ${ }^{17},{ }^{18}$ Compared with all the exporting and importing firms under the ordinary-trade regime reported by the Customs Database, the matching rate of our sample (in terms of the number of firms) covers $45.3 \%$ of exporters and $40.2 \%$ of importers, corresponding to $52.4 \%$ of total export value and $42 \%$ of total import value reported by the Customs Database. ${ }^{19}$

\subsection{Measurement}

In what follows, we will describe how to measure the main variables in which we are interested: tariffs on imported intermediate goods, tariffs on imported final goods, revealed comparative advantage (RCA) and the firm productivity.

\subsubsection{Measures of Tariffs}

\section{Estimation of Import Tariffs}

\section{Method 1: Input Tariffs and Output Tariffs}

To be consistent with the literature, we mainly use the industry-level input tariffs to measure the tariffs of imported inputs, and the industry-level output tariffs to measure the tariffs on imported outputs, where these tariffs are estimated with the help of the input-output table. We shall call them "input tariffs" and "output tariffs". We first extract the import tariff rate charged by Chinese customs for each harmonized system (HS) 8-digit good from the WTO data base. In order to use the InputOutput (IO) table of Chinese industries to establish the linkage between inputs and outputs, we map the harmonized system (HS) 8-digit tariff onto the 3 -digit IO industries. ${ }^{20}$ We then compute the output tariffs at the 3-digit IO industry level by taking the simple average of the import tariffs of the HS

\footnotetext{
${ }^{17}$ In the NBSC Database, firms are identified by their corporate representative codes and contact information. In the Customs Database, firms are identified by their corporate custom codes and contact information. These two coding systems are neither consistent, nor transferable with each other.

${ }^{18}$ Our matching procedure is done in three steps. First, the vast majority of firms (89.3\%) are matched by company names exactly. Second, an additional $10.1 \%$ are matched by telephone number and zip code exactly. Finally, the remaining $0.6 \%$ of firms are matched by telephone number and contact person name exactly.

${ }^{19}$ Compared with the manufacturing exporting firms in the NBSC Database, the matching rate of our sample (in terms of the number of firms) varies from $54 \%$ to $63 \%$ between 2001 and 2006 , which covers more than $60 \%$ of total value of firm exports in the manufacturing sector reported by the NBSC Database.

${ }^{20}$ As our data sample covers the time between 2001 and 2006, we adopt the input-output table from 2002 . There are 122 sectors, in which 71 sectors are manufacturing sectors.
} 
8-digit codes within each 3-digit IO industry. Following Amiti and Konings (2007), we use an inputcost-weighted average output tariffs to calculate the input tariff for each industry $i$ as

$$
\tau_{i, t}^{\text {input }}=\sum_{k} s_{k i} \tau_{k, t}^{\text {output }}
$$

where $\tau_{k, t}^{\text {output }}$ is the tariff in industry $k$ at time $t$, and $s_{k i}$ is the weight of industry $k$ in the input cost of industry $i$ from the IO table. Since our production data utilize the CIC (Chinese Industrial Classification) 4-digit code, we map the input and output tariffs at the IO 3-digit industry level onto the CIC 4-digit industries. We then obtain a set of input and output tariffs at CIC 4-digit level, which will serve as the major measures of tariffs of imported intermediate goods and imported final goods respectively, for the empirical tests in our paper.

The advantage of these input and output tariffs measurements is that they can account for the input-output linkage between the industries. These measures of tariffs are comprehensive in capturing the effect of imported inputs since firms might acquire some of the foreign intermediate goods from other Chinese importing firms and this kind of indirect importing behavior can be well captured by the IO table.

\section{Method 2: Imported Intermediate-good Tariffs and Imported Final-good Tariffs}

An alternative way to estimate the imported-input tariffs and imported-output tariffs is to calculate them directly using firm-level data. To do this, we use the merged data built upon the NBSC firmlevel database and the Customs database to calculate the industry-level "imported intermediate-good tariffs" and "imported final-good tariffs". ${ }^{21}$ We construct imported intermediate-good tariffs using information on the exact initial bundle of intermediate goods imported by firms. Based on the Broad Economic Categories (BEC) classification, we can distinguish between imported intermediate goods and imported final goods. Thus, we can compute a weighted average industry-level measure of tariff on imported intermediate goods in final-good sector $k$ in year $t$ as $d u t y_{i k, t}=\sum_{h \in Z} w_{h k, t} \tau_{h k, t}$, where the weight $w_{h k, t}$ is the share of imported intermediate HS6 product $h$ in the total imported value of intermediate goods for ordinary (non-processing) trade imported by the firms in industry $k$ in year $t, \tau_{h k, t}$ is the tariff on intermediate HS6 product $h$ imported by firms in industry $k$ in year $t .^{22}$ The imported final-good tariffs should be the average of all relevant tariffs weighted by the share of each final product's domestic sales. However, data on product-level domestic sales are unavailable. Thus, we adopt a less satisfactory approach by using the share of a firms' export of the product $h$ in the industry $k$ to substitute for the share of its domestic sales, as in Yu (2015). Then, the weighted average industry-level measure of tariff on imported final-goods (i.e. imported outputs) in sector $k$ in year $t$ is computed as $d u t y_{o k, t}=\sum_{h \in Z} v_{h k, t} \tau_{h k, t}$, where the weight $v_{h k, t}$ is the share of exported HS6 final good $h$ in the total exported value of final goods by the matched ordinary-trade firms in sector $k$ in year $t$, $\tau_{h k, t}$ is the tariff on imported HS6 final good $h$ in industry $k$ in year $t$.

\footnotetext{
${ }^{21}$ The shortcoming of this method is that the NBSC firm-level database only includes large firms and there are information losses during the matching process. This may lead to sample selection bias.

${ }^{22}$ Imported intermediate goods for processing trade are not subject to tariffs.
} 


\section{Estimation of Export Tariffs}

For robustness check, we also control for the export tariffs, as it can be argued that they also affect the left hand side variables in our regressions. To calculate the export tariff, $d u t y_{e k, t}$, we first use the export value to each country to calculate the weighted average export tariff for each HS6 product faced by Chinese exporting firms. Here, we use the ad valorem tariff imposed by the destination country when Chinese firms export. Then we calculate the simple average of the export tariffs within each 3-digit IO industry and then map the IO 3-digit export tariffs onto the CIC 4-digit industries. In contrast to the import tariffs, export tariffs did not change too much. On average, it decreased from $8.227 \%$ to $6.465 \%$ during the period 2001-2006.

Our main estimation results are based on import tariff estimation Method 1, the industry-level "input tariffs" and "output tariffs" calculated based on the input-output table. For robustness check, we also use import tariff estimation Method 2: industry-level "imported intermediate-good tariffs" and "imported final-good tariffs" estimated from the merged firm-level data. Figure 2 below presents the time trend of the average magnitude across 4-digit CIC sectors of each type of tariff we described above during 2001-2006. It shows that there were relatively large drops in the imported-input and importoutput tariff rates since China joined WTO in 2001. However, the export tariff rate did not drop much.

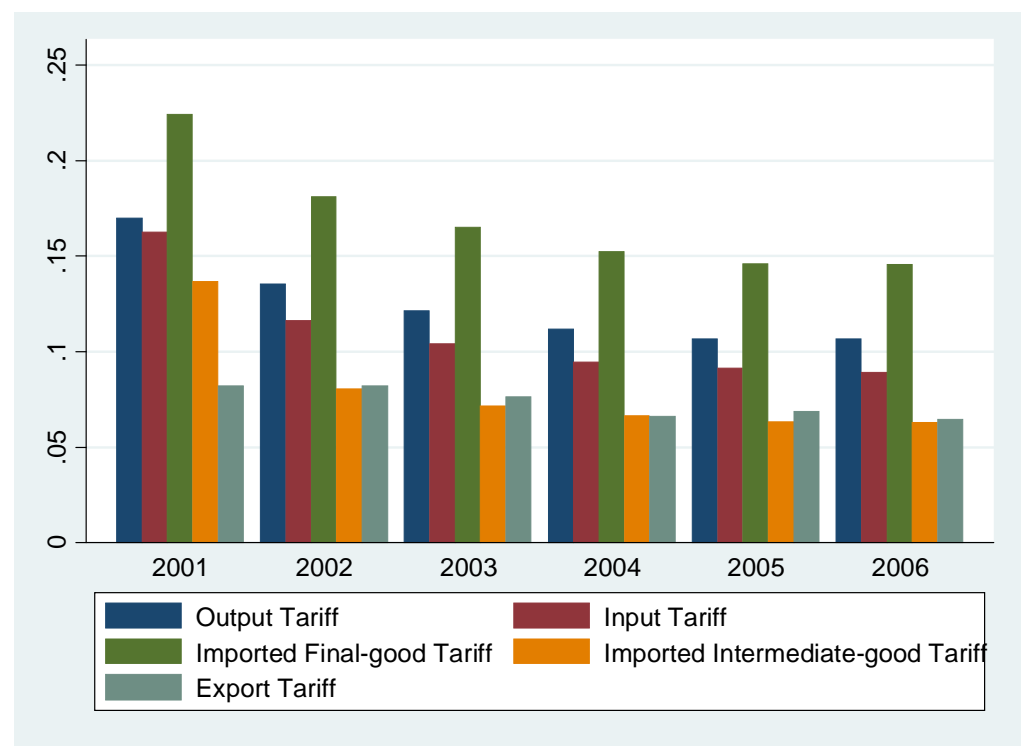

Figure 2: Average Magnitude across the CIC 4-digit Industries of Each Type of Tariff (Input tariff and output tariff based on Input-Output tables; Imported intermediate-good tariffs and imported final-good tariffs based on the merged firm-level data; and export tariffs) 


\subsubsection{Measures of RCAs}

The second most important variable we need to proxy for is the measure of comparative advantage of a sector. The Balassa (1965) index provides a measure of the "revealed" comparative advantage (RCA) of a sector in a country. Since then, the Balassa index has undergone several modifications. Based on our theory, we can show that these several measures of revealed comparative advantage is positively related to $B_{3 k} a_{k}^{\gamma}$. Hence, we use them to proxy for $B_{3 k} a_{k}^{\gamma}$. In what follows, we shall explain the different measures of revealed comparative advantage developed by Balassa and others. The Balassa (1965) index in industry $\mathrm{i}$ is expressed as:

$$
\mathrm{RCA}_{1}=\frac{X_{c k}}{X_{c}} / \frac{X_{w k}}{X_{w}}
$$

where $X_{c k}$ and $X_{w k}$ represent respectively the exports from China and that from the rest of world in the industry $k ; X_{c}$ and $X_{w}$ represent respectively the exports from China and that from the rest of world in all industries. The index $\mathrm{RCA}_{1}$ is the ratio of China's exports in industry $k$ relative to its total exports, to the corresponding measure for the rest of world. Therefore, a higher $\mathrm{RCA}_{1}$ means stronger revealed comparative advantage. However, the Balassa index is criticized for omitting imports in its analysis. To address this issue, we use a second index, which is expressed as:

$$
\mathrm{RCA}_{2}=\frac{X_{c k}}{X_{c}} / \frac{X_{w k}}{X_{w}}-\frac{M_{c k}}{M_{c}} / \frac{M_{w k}}{M_{w}}
$$

where $M_{c k}$ and $M_{w k}$ represent respectively the imports by China and the rest of world in industry $k$; $M_{c}$ and $M_{w}$ represent respectively the imports by China and the rest of world in all industries. The construction of this index requires the data of exports and imports of China and those of the rest of world. Another index of RCA, which is based only on China's exports and imports, is expressed as:

$$
\mathrm{RCA}_{3}=\frac{X_{c k}-M_{c k}}{X_{c k}+M_{c k}}
$$

Two more indexes of RCA, which are based only on China's exports and imports, are:

$$
\begin{aligned}
\mathrm{RCA}_{4} & =\frac{X_{c k}}{X_{c}} / \frac{M_{c k}}{M_{c}} \\
\mathrm{RCA}_{5} & =\ln \left(\frac{X_{c k}}{X_{c}} / \frac{M_{c k}}{M_{c}}\right) * 100
\end{aligned}
$$

There is some concern that the above measures of revealed comparative advantage is a proxy for $B_{3 k} a_{k}^{\gamma}$, which is related to the current tariffs. In order to address the potential endogeneity issue, we use the trade flows data from CEPII in the year 2000 to calculate the above five RCA indexes. We also use the log of ranks of the RCA indexes instead of the RCA indexes themselves for further robustness checks. It turns out that the ranks of $\mathrm{RCA}_{3}, \mathrm{RCA}_{4}$ and $\mathrm{RCA}_{5}$ are same. Panel $\mathrm{A}$ in Table $\mathrm{A} 2$ in the appendix shows the correlation coefficient among the above five RCA indexes and Panel $\mathrm{B}$ shows the correlation coefficients among the log ranks of different RCA indexes. From the table we can see that the above five RCA indexes are highly correlated. Panel C of Table A2 reports the summary statistics of these RCA indexes. 


\subsubsection{Measures of TFP}

As we need to control for firm productivity, we use the augmented Olley-Pakes method (Olley and Pakes, 1996) to estimate firm's productivity (TFP). ${ }^{23}$ The augmentation takes into account a number of additional firm level decisions. As in Amiti and Konings (2007), we include an export dummy (equal to one for exporters and zero otherwise) and a WTO dummy (i.e., one for a year in or after 2002 and zero otherwise) in the Olley-Pakes estimation. ${ }^{24}$ We use value-added to measure production output, and deflate firms' inputs (e.g., capital) and value-added using the input price deflators and output price deflators from Brandt, Biesebroeck and Zhang (2012). ${ }^{25}$ Then we construct the real investment variable by adopting the perpetual inventory method to analyze the law of motion for real capital and real investment. To measure the depreciation rate, we use each firm's real depreciation rate provided by the NBSC firm-level database.

\section{$5 \quad$ Empirical Results}

In this section, we report our main empirical results with regard to Propositions 2-4. Considering the fact that China's trade liberalization prompted by the accession to WTO mainly led to reduction in import tariffs (for both intermediate goods and final goods) and the majority of Chinese imports were intermediate goods rather than final goods, our study focuses on the effects of imported-input trade liberalization.

\subsection{Main Results}

\subsubsection{Testing Proposition 3}

Table 1 reports the regression results regarding the probability of entry into the export market. ${ }^{26}$ According to our Proposition 3, the probability of entry into the export market for previously non-exporting firms should be higher in sectors with stronger comparative advantage following trade liberalization in imported intermediate goods. As predicted, the coefficients of the interactive term "input tariff change x RCA" in columns 1 to 8 in Table 1 are significantly negative. In Table 1, we control for the changes of input- and output-tariffs, revealed comparative advantage, and some firm-level characteristic such

\footnotetext{
${ }^{23}$ Our results are robust to different approaches in estimating TFP, including the OLS method, the Levinsohn-Petrin method (Levinsohn and Petrin, 2003), and the Ackerberg-Caves-Frazer augmented O-P and L-P methods (Ackerberg, Caves and Frazer, 2006), and value added per worker. These results are available upon request.

${ }^{24}$ We do not add any import dummy since the NBSC firm-level database does not have a firm's import-decision information.

${ }^{25}$ The output deflators are constructed using "reference price" information from China's Statistical Yearbooks, and the input deflators are constructed based on output deflators and China's national input-output table (2002). The data can be accessed via http://www.econ.kuleuven.be/public/N07057/CHINA/appendix/.

${ }^{26}$ To judge whether or not the firms in two consecutive years are same firm, we first link the firms by firm ID. Then, we use additional information to link them. We create new codes that use various combinations of firm name (in Chinese), name of legal person representative (in Chinese), geographic code, phone number.
} 
as, TFP, capital intensity, average wage and firm size (measured by total employment). Columns 1-5 correspond to regressions using $\mathrm{RCA}_{1}, \mathrm{RCA}_{2}, \mathrm{RCA}_{3}, \mathrm{RCA}_{4}, \mathrm{RCA}_{5}$, respectively as the RCA index. Moreover, we also use the log ranks of the RCA indexes instead of the RCA indexes themselves for robustness check. Columns 6-8 correspond to regressions using the log ranks of $\mathrm{RCA}_{1}, \mathrm{RCA}_{2}$ and $\mathrm{RCA}_{3}$ as the RCA index. The ranks of $\mathrm{RCA}_{4}$ and $\mathrm{RCA}_{5}$ are same as the rank of $\mathrm{RCA}_{3} \cdot{ }^{27}$ Besides, Table 1 shows that the LHS variable increases with a firm's productivity, employment, capital-labor ratio, and wage per worker. All in all, the results in Table 1 offer support for Proposition 3. Column 1 shows that a one unit increase in the RCA index (from its mean) for an average firm in the average industry raises the impact of imported input tariff change on the probability of entry into the export market by the firm by $1.14 \%$. Columns $2-8$ shows that if we use other measures of RCA, the magnitudes become $1.05 \%, 3.76 \%, 0.49 \%, 0.02 \%, 1.21 \%, 0.45 \%, 1.22 \%$ respectively. ${ }^{28}$ This means that the impacts of imported-input tariff changes are economically significant besides being statistically significant.

\footnotetext{
${ }^{27}$ If we use the ranks of RCA indexes or the dummy variables which equals to one when it is larger than median and equals to zero otherwise, all results continue to hold.

${ }^{28}$ In the logit model, we have $\operatorname{Pr}\left(\right.$ Export $_{f, t+1}=1 \mid$ Export $\left._{f, t}=0\right)=\Phi(\mathbf{X} \beta)$, where $\mathbf{X} \beta$ represents the linear combination of dependent variables on the right hand side of the estimation equation. As a result, the partial effect of one unit increase in the RCA index is equal to $\Phi(\mathbf{X} \beta)[1-\Phi(\mathbf{X} \beta)]\left(\beta_{2} \triangle d u t y_{i k, t}+\beta_{4}\right)$. Plugging the estimated coefficients from Table 1 and the means of the dependent variables into the expression, we obtain the effect of a one unit increase in the RCA index on the probability of entry into the export market for an average firm in the average industry in our sample.
} 


\begin{tabular}{|c|c|c|c|c|c|c|c|c|}
\hline RCA index & $\mathrm{BCA}_{1}$ & $\mathrm{BCA}$ & $\mathrm{BCA}$ & $\mathrm{BCA}$ & $\mathrm{BCA}_{-}$ & Banl & Bantro & Boplo \\
\hline \multirow{3}{*}{ Regressor } & & & & & & & & \\
\hline & Logit & Logit & Logit & Logit & Logit & Logit & Logit & Logit \\
\hline & $(1)$ & $(2)$ & $(3)$ & (4) & $(5)$ & (6) & (7) & (8) \\
\hline \multirow[t]{2}{*}{$\Delta$ duty $_{i k}$} & $2.647^{* *}$ & -0.082 & 0.775 & 1.114 & -0.216 & 12.781 & $6.336^{* *}$ & 11.448 \\
\hline & $(1.174)$ & $(0.922)$ & $(1.290)$ & $(0.934)$ & $(0.880)$ & $(8.141)$ & $(3.019)$ & $(7.077)$ \\
\hline \multirow{2}{*}{$\Delta$ duty $_{i k} \times \mathbf{R C A}$} & $-1.722^{* * *}$ & $-1.132^{* * *}$ & $-5.127^{* * *}$ & $-0.417^{* * *}$ & $-0.018^{* * *}$ & $-3.726^{*}$ & $-2.325^{* * *}$ & $-3.599^{* *}$ \\
\hline & $(0.296)$ & $(0.236)$ & $(1.724)$ & $(0.082)$ & $(0.004)$ & $(2.034)$ & $(0.807)$ & $(1.801)$ \\
\hline \multirow[t]{2}{*}{$\Delta$ duty $_{o k}$} & -1.682 & -0.259 & -0.603 & -0.200 & -1.202 & -3.242 & 1.549 & 0.164 \\
\hline & $(3.236)$ & $(3.108)$ & $(3.400)$ & $(3.041)$ & (3.397) & $(3.894)$ & $(2.980)$ & $(3.310)$ \\
\hline \multirow[t]{2}{*}{$\mathrm{RCA}$} & $0.124^{* * *}$ & $0.109 * * *$ & $0.421^{* * *}$ & $0.056^{*}$ & $0.002^{* * *}$ & $0.310^{* * *}$ & $0.232^{* * *}$ & $0.216^{* * *}$ \\
\hline & $(0.046)$ & $(0.029)$ & $(0.140)$ & $(0.029)$ & $(0.001)$ & $(0.077)$ & $(0.060)$ & $(0.073)$ \\
\hline \multirow[t]{2}{*}{$\mathrm{TFP}$} & $0.037^{*}$ & $0.039^{* *}$ & $0.038^{*}$ & $0.038^{*}$ & $0.039^{* *}$ & $0.038^{*}$ & $0.039^{* *}$ & $0.038^{*}$ \\
\hline & $(0.020)$ & $(0.020)$ & $(0.020)$ & $(0.020)$ & $(0.020)$ & $(0.020)$ & $(0.020)$ & $(0.020)$ \\
\hline \multirow[t]{2}{*}{$\log (\mathrm{Empl})$} & $0.299^{* * *}$ & $0.303^{* * *}$ & $0.305^{* * *}$ & $0.297^{* * *}$ & $0.304^{* * *}$ & $0.301^{* * *}$ & $0.308^{* * *}$ & $0.303^{* * *}$ \\
\hline & $(0.019)$ & $(0.018)$ & $(0.018)$ & $(0.019)$ & $(0.019)$ & $(0.019)$ & $(0.018)$ & $(0.018)$ \\
\hline \multirow[t]{2}{*}{$\log (\mathrm{K} / \mathrm{L})$} & 0.025 & 0.026 & 0.027 & 0.025 & 0.027 & 0.028 & 0.027 & 0.026 \\
\hline & $(0.018)$ & $(0.018)$ & $(0.018)$ & $(0.018)$ & $(0.018)$ & $(0.018)$ & $(0.018)$ & $(0.018)$ \\
\hline \multirow[t]{2}{*}{$\log$ (Wage) } & $0.294^{* * *}$ & $0.289^{* * *}$ & $0.290^{* * *}$ & $0.293^{* * *}$ & $0.290 * * *$ & $0.295^{* * *}$ & $0.286^{* * *}$ & $0.292^{* * *}$ \\
\hline & $(0.026)$ & $(0.026)$ & $(0.026)$ & $(0.026)$ & $(0.026)$ & $(0.026)$ & $(0.026)$ & $(0.026)$ \\
\hline Year fixed effect & Yes & Yes & Yes & Yes & Yes & Yes & Yes & Yes \\
\hline Industry fixed effect & Yes & Yes & Yes & Yes & Yes & Yes & Yes & Yes \\
\hline Observations & 370102 & 370102 & 370102 & 370102 & 370102 & 370102 & 370102 & 370102 \\
\hline Log likelihood & -79350 & -79299 & -79330 & -79374 & -79307 & -79248 & -79320 & -79366 \\
\hline \multicolumn{9}{|c|}{ Note: ${ }^{* * *}$ Significant at the $1 \%$ level; ${ }^{* *}$ Significant at the $5 \%$ level; ${ }^{*}$ Significant at the $10 \%$ level. } \\
\hline & & & & & & & & \\
\hline
\end{tabular}

\section{Using alternative measures of imported-input and imported-output tariffs}

In Table 1, all results are based on import tariff estimation Method 1: input tariffs and output tariffs as described in section 4.3.1. As a robustness check, we use import tariff estimation Method 2: imported intermediate-good tariffs and imported final-good tariffs to estimate the import tariffs and re-run the regressions. The results are reported in Table A3 in Appendix C. As shown in Table A3, the coefficients of the interaction of imported-input tariff change and RCA are negative in all columns. All of them are significant except for Column 7. Thus, the robustness checks further support our Proposition 3. 


\subsubsection{Testing Propositions 2 and 4}

In a similar format as in Tables 1, Tables 2 and 3 report the regression results regarding the change in the fraction of exporting firms and the change in the share of exporting revenue in total revenue, respectively. The theory predicts that these impacts are larger in the sectors with stronger comparative advantage. As predicted, the coefficients of the interactive term "input tariff change x RCA" are negative in all columns in both tables. In Tables 2 and 3, we control for the change of input and output tariffs, revealed comparative advantage, and some industry-level characteristics such as average TFP, capital intensity, average wage and average firm size (measured by total employment). Columns 1-5 correspond to regressions using $\mathrm{RCA}_{1}, \mathrm{RCA}_{2}, \mathrm{RCA}_{3}, \mathrm{RCA}_{4}, \mathrm{RCA}_{5}$, respectively as the RCA index. Columns 6-8 correspond to regressions using the $\log$ ranks of $\mathrm{RCA}_{1}, \mathrm{RCA}_{2}$ and $\mathrm{RCA}_{3}$ as the $\mathrm{RCA}$ index. ${ }^{29}$

\begin{tabular}{|c|c|c|c|c|c|c|c|c|}
\hline \multicolumn{9}{|c|}{ Table 2: Change in fraction of exporting firms } \\
\hline RCA index & $\mathrm{RCA}_{1}$ & $\mathrm{RCA}_{2}$ & $\mathrm{RCA}_{3}$ & $\mathrm{RCA}_{4}$ & $\mathrm{RCA}_{5}$ & $\operatorname{Rank}_{1}$ & $\operatorname{Rank}_{2}$ & Rank $_{3}$ \\
\hline \multirow[t]{2}{*}{ Regressor } & OLS & OLS & OLS & OLS & OLS & OLS & OLS & OLS \\
\hline & $(1)$ & $(2)$ & $(3)$ & $(4)$ & $(5)$ & $(6)$ & (7) & (8) \\
\hline \multirow[t]{2}{*}{$\Delta$ duty $_{i k}$} & 0.007 & $-0.080^{* *}$ & $-0.094^{* * *}$ & -0.026 & $-0.119^{* * *}$ & $0.166^{*}$ & $0.295^{* * *}$ & 0.077 \\
\hline & $(0.049)$ & $(0.036)$ & $(0.035)$ & $(0.051)$ & $(0.037)$ & $(0.093)$ & $(0.109)$ & $(0.077)$ \\
\hline \multirow[t]{2}{*}{$\Delta$ duty $_{i k} \times \mathbf{R C A}$} & $-0.104^{* * *}$ & $-0.089^{* * *}$ & $-0.116^{* *}$ & $-0.036^{* *}$ & $-0.001^{* * *}$ & $-0.092^{* * *}$ & $-0.124^{* * *}$ & $-0.064^{* *}$ \\
\hline & $(0.031)$ & $(0.026)$ & $(0.046)$ & $(0.015)$ & $(0.000)$ & $(0.030)$ & $(0.035)$ & $(0.026)$ \\
\hline \multirow[t]{2}{*}{$\Delta$ duty $_{o k}$} & -0.094 & -0.078 & -0.023 & -0.051 & -0.041 & -0.059 & -0.002 & -0.003 \\
\hline & $(0.108)$ & $(0.106)$ & $(0.109)$ & $(0.107)$ & $(0.109)$ & $(0.125)$ & $(0.104)$ & $(0.108)$ \\
\hline \multirow[t]{2}{*}{$\mathrm{RCA}$} & -0.002 & -0.000 & $0.006^{*}$ & -0.000 & 0.000 & -0.001 & 0.003 & $0.003^{*}$ \\
\hline & $(0.001)$ & $(0.001)$ & $(0.004)$ & $(0.001)$ & $(0.000)$ & $(0.002)$ & $(0.002)$ & $(0.002)$ \\
\hline \multirow[t]{2}{*}{ TFP } & $0.011^{* * *}$ & $0.011^{* * *}$ & $0.011^{* * *}$ & $0.012^{* * *}$ & $0.011^{* * *}$ & $0.012^{* * *}$ & $0.011^{* * *}$ & $0.011^{* * *}$ \\
\hline & $(0.004)$ & $(0.004)$ & $(0.004)$ & $(0.004)$ & $(0.004)$ & $(0.004)$ & $(0.004)$ & $(0.004)$ \\
\hline \multirow[t]{2}{*}{$\log (\mathrm{Empl})$} & $-0.003^{* * *}$ & $-0.003^{* * *}$ & $-0.003^{* * *}$ & $-0.003^{* * *}$ & $-0.003^{* * *}$ & $-0.003^{* * *}$ & $-0.003^{* * *}$ & $-0.003^{* * *}$ \\
\hline & $(0.001)$ & $(0.001)$ & $(0.001)$ & $(0.001)$ & $(0.001)$ & $(0.001)$ & $(0.001)$ & $(0.001)$ \\
\hline \multirow[t]{2}{*}{$\log (\mathrm{K} / \mathrm{L})$} & 0.000 & 0.000 & 0.001 & 0.000 & 0.001 & -0.000 & 0.001 & 0.001 \\
\hline & $(0.002)$ & $(0.002)$ & $(0.002)$ & $(0.002)$ & $(0.002)$ & $(0.002)$ & $(0.002)$ & $(0.002)$ \\
\hline \multirow[t]{2}{*}{ log(Wage) } & $-0.010^{*}$ & $-0.009^{*}$ & -0.009 & $-0.010^{*}$ & $-0.009 *$ & -0.009 & -0.009 & -0.009 \\
\hline & $(0.006)$ & $(0.006)$ & $(0.006)$ & $(0.006)$ & $(0.006)$ & $(0.006)$ & $(0.006)$ & $(0.006)$ \\
\hline Year fixed effect & Yes & Yes & Yes & Yes & Yes & Yes & Yes & Yes \\
\hline Industry fixed effect & Yes & Yes & Yes & Yes & Yes & Yes & Yes & Yes \\
\hline Observations & 2065 & 2065 & 2065 & 2065 & 2065 & 2065 & 2065 & 2065 \\
\hline R-squared & 0.064 & 0.064 & 0.062 & 0.063 & 0.062 & 0.061 & 0.062 & 0.061 \\
\hline \multicolumn{9}{|c|}{ Note: ${ }^{* * *}$ Significant at the $1 \%$ level; ${ }^{* *}$ Significant at the $5 \%$ level; ${ }^{*}$ Significant at the $10 \%$ level. } \\
\hline & & & & & & & & \\
\hline
\end{tabular}

${ }^{29}$ Column 1 in Tables 2 and 3 imply that a one unit increase in RCA raises the impact of a change of tariff on importedinput on the fraction of exporting firms and the share of export revenue in total revenue both by 0.15 percent. 


\begin{tabular}{|c|c|c|c|c|c|c|c|c|}
\hline \multicolumn{9}{|c|}{ Table 3: Change in share of export revenue in total revenue } \\
\hline RCA index & $\mathrm{RCA}_{1}$ & $\mathrm{RCA}_{2}$ & $\mathrm{RCA}_{3}$ & $\mathrm{RCA}_{4}$ & $\mathrm{RCA}_{5}$ & $\operatorname{Rank}_{1}$ & Rank $_{2}$ & Rank $_{3}$ \\
\hline \multirow[t]{2}{*}{ Regressor } & OLS & OLS & OLS & OLS & OLS & OLS & OLS & OLS \\
\hline & (1) & $(2)$ & $(3)$ & (4) & $(5)$ & (6) & (7) & (8) \\
\hline \multirow[t]{2}{*}{$\Delta$ duty $_{i k}$} & 0.010 & -0.076 & $-0.078^{*}$ & -0.033 & $-0.112^{* *}$ & $0.280^{* *}$ & $0.415^{* * *}$ & $0.165^{* *}$ \\
\hline & $(0.045)$ & $(0.048)$ & $(0.046)$ & $(0.058)$ & $(0.055)$ & $(0.114)$ & $(0.147)$ & $(0.083)$ \\
\hline \multirow[t]{2}{*}{$\Delta$ duty $_{i k} \times \mathbf{R C A}$} & $-0.104^{* * *}$ & $-0.088^{* * *}$ & $-0.157^{* * *}$ & $-0.031^{* * *}$ & $-0.001^{* * *}$ & $-0.127^{* * *}$ & $-0.157^{* * *}$ & $-0.091^{* * *}$ \\
\hline & $(0.032)$ & $(0.027)$ & $(0.058)$ & $(0.010)$ & $(0.000)$ & $(0.044)$ & $(0.053)$ & $(0.034)$ \\
\hline \multirow[t]{2}{*}{$\Delta$ duty $_{o k}$} & -0.120 & -0.099 & -0.080 & -0.058 & -0.094 & -0.161 & -0.045 & -0.054 \\
\hline & $(0.103)$ & $(0.100)$ & $(0.106)$ & $(0.107)$ & $(0.105)$ & $(0.123)$ & $(0.102)$ & $(0.105)$ \\
\hline \multirow[t]{2}{*}{$\mathrm{RCA}$} & 0.000 & 0.001 & $0.010^{* *}$ & 0.001 & $0.000^{* *}$ & 0.001 & $0.003^{*}$ & $0.004^{* *}$ \\
\hline & $(0.002)$ & $(0.001)$ & $(0.004)$ & $(0.001)$ & $(0.000)$ & $(0.001)$ & $(0.002)$ & $(0.002)$ \\
\hline \multirow[t]{2}{*}{ TFP } & 0.003 & 0.003 & 0.003 & 0.003 & 0.003 & 0.003 & 0.002 & 0.003 \\
\hline & $(0.004)$ & $(0.004)$ & $(0.004)$ & $(0.004)$ & $(0.004)$ & $(0.004)$ & $(0.004)$ & $(0.004)$ \\
\hline \multirow[t]{2}{*}{$\log (\mathrm{Empl})$} & $-0.005^{* * *}$ & $-0.005^{* * *}$ & $-0.005^{* * *}$ & $-0.005^{* * *}$ & $-0.005^{* * *}$ & $-0.005^{* * *}$ & $-0.005^{* * *}$ & $-0.005^{* * *}$ \\
\hline & $(0.001)$ & $(0.001)$ & $(0.001)$ & $(0.001)$ & $(0.001)$ & $(0.001)$ & $(0.001)$ & $(0.001)$ \\
\hline \multirow[t]{2}{*}{$\log (\mathrm{K} / \mathrm{L})$} & $0.007 * * *$ & $0.008^{* * *}$ & $0.008^{* * *}$ & $0.007^{* * *}$ & $0.008^{* * *}$ & $0.007^{* * *}$ & $0.008^{* * *}$ & $0.008^{* * *}$ \\
\hline & $(0.002)$ & $(0.002)$ & $(0.002)$ & $(0.002)$ & $(0.002)$ & $(0.002)$ & $(0.002)$ & $(0.002)$ \\
\hline \multirow[t]{2}{*}{$\log$ (Wage) } & -0.000 & -0.000 & -0.000 & -0.001 & -0.001 & -0.000 & -0.000 & -0.000 \\
\hline & $(0.007)$ & $(0.007)$ & $(0.007)$ & $(0.007)$ & $(0.007)$ & $(0.007)$ & $(0.007)$ & $(0.007)$ \\
\hline Year fixed effect & Yes & Yes & Yes & Yes & Yes & Yes & Yes & Yes \\
\hline Industry fixed effect & Yes & Yes & Yes & Yes & Yes & Yes & Yes & Yes \\
\hline Observations & 2065 & 2065 & 2065 & 2065 & 2065 & 2065 & 2065 & 2065 \\
\hline R-squared & 0.062 & 0.063 & 0.062 & 0.061 & 0.062 & 0.060 & 0.062 & 0.061 \\
\hline \multicolumn{9}{|c|}{ Note: ${ }^{* * *}$ Significant at the $1 \%$ level; ${ }^{* *}$ Significant at the $5 \%$ level; ${ }^{*}$ Significant at the $10 \%$ level. } \\
\hline & & & & & & & & \\
\hline
\end{tabular}

\section{Using alternative measures of imported-input and imported-output tariffs}

In Tables 2 and 3, all results are based on the input- and output-tariffs described in section 4.3.1. Similar robustness checks as reported in Table A3 are carried out and reported in Tables A4 and A5 in Appendix C. We can see that the coefficients of the interaction term of imported-input tariff reduction and RCA in all columns are negative. All of them are significant except for column 8 in Tables A4 and A5. Thus, the robustness checks further support our Propositions 2 and 4.

\subsection{Further Tests}

In Table 4, we report the results when we control for the interaction term between imported-output tariff change and RCA, $\Delta \mathbf{d u t y}_{o k} \times \mathbf{R C A}$, and the interaction term between export tariff change and 
RCA, $\Delta$ duty $_{e k} \times \mathbf{R C A}$. In columns 1,4 and 7, we add the term $\Delta$ duty $_{o k} \times \mathbf{R C A}$. In column $2-3,5-6$ and $8-9$, we add the term $\Delta \mathbf{d u t y}_{e k} \times \mathbf{R C A}$.

In Table 4, we only report the results based on the index $\mathrm{RCA}_{1}$. For other indexes, the results are qualitatively the same. Columns 1-3 correspond to the probability of exporting (Proposition 3); columns 4-6 correspond to the change in fraction of exporting firms (Proposition 2); columns 7- 9 correspond to the change in share of export revenue (Proposition 4). The coefficients of the term "imported-input tariff change x RCA", $\Delta \mathbf{d u t y}_{i k} \times \mathbf{R C A}$, are still significantly negative in all columns. The coefficients of the interaction of imported-output tariff change and RCA, $\Delta \mathbf{d u t y}_{o k} \times \mathbf{R C A}$, are significantly positive. The effect of RCA on the impact of imported-input tariff reduction and that on the impact of imported-output tariff reduction are opposite. This is because the reduction in importedinput tariffs leads to potential cost reduction for domestic final good producers, which benefits more the final-good firms in the industries with stronger comparative advantage, as the comparative advantage of the firms can be further reinforced. The reduction in imported-output tariff, on the other hand, strengthens the competitiveness of foreign final-good producers, which leads to tougher competition in the foreign market, thus hurting the domestic final-good exporters. ${ }^{30}$ The coefficients of the interaction of export tariff change and RCA are insignificant, as the variation in changes of export tariff is too small. The above results by and large further support our theoretical predictions.

\footnotetext{
${ }^{30}$ The effect of trade liberalization in imported final goods on the fraction of firms that export satisfies $\frac{d\left(\frac{\bar{\varphi}_{d k}}{\bar{\varphi}_{x k}}\right)^{\gamma}}{d \tau_{x k}^{*}}=$ $\frac{f}{f_{x}}\left[\frac{B_{2 k}^{-1}}{B_{1 k}-B_{3 k}\left(a_{k}\right)^{\gamma}}\right] \frac{\gamma}{\tau_{x k}^{*}}$, which is positive and increases with $B_{3 k}\left(a_{k}\right)^{\gamma}$ (as its magnitude is larger in the sectors with comparative advantage). Hence, the fraction of firms that export decreases with reduction in tariffs on imported final goods. At the same time, the probability of entry into the export market for a previously non-exporting firm and the revenue share from exporting would also fall.
} 


\begin{tabular}{|c|c|c|c|c|c|c|c|c|c|}
\hline \multicolumn{10}{|c|}{ Table 4: Controlling for More Tariff Changes } \\
\hline \multirow[b]{2}{*}{ Regressor } & \multicolumn{3}{|c|}{ The probability of entry } & \multicolumn{3}{|c|}{ Change in export firms ratio } & \multicolumn{3}{|c|}{ Change in export revenue ratio } \\
\hline & Logit & Logit & Logit & OLS & OLS & OLS & OLS & OLS & OLS \\
\hline & (1) & $(2)$ & (3) & (4) & (5) & (6) & (7) & (8) & (9) \\
\hline \multirow[t]{2}{*}{$\Delta$ duty $i k$} & 1.735 & $2.707^{* *}$ & 1.747 & -0.009 & 0.004 & -0.012 & -0.010 & 0.015 & -0.006 \\
\hline & $(1.210)$ & $(1.192)$ & $(1.232)$ & $(0.049)$ & $(0.049)$ & $(0.050)$ & $(0.044)$ & $(0.044)$ & $(0.043)$ \\
\hline \multirow{2}{*}{$\Delta$ duty $_{i k} \times \mathbf{R C A}$} & $-0.684^{* *}$ & $-1.744^{* * *}$ & $-0.663^{*}$ & $-0.079 * *$ & $-0.103^{* * *}$ & $-0.079^{* *}$ & $-0.073^{* *}$ & $-0.105^{* * *}$ & $-0.074^{* *}$ \\
\hline & $(0.346)$ & $(0.303)$ & $(0.360)$ & $(0.033)$ & $(0.031)$ & $(0.032)$ & $(0.036)$ & $(0.032)$ & $(0.035)$ \\
\hline \multirow[t]{2}{*}{$\Delta$ duty $_{o k}$} & 0.610 & -2.084 & 0.093 & -0.058 & -0.078 & -0.042 & -0.075 & -0.148 & -0.101 \\
\hline & $(3.178)$ & $(3.208)$ & $(3.128)$ & $(0.108)$ & $(0.108)$ & $(0.108)$ & $(0.098)$ & $(0.104)$ & $(0.101)$ \\
\hline \multirow[t]{2}{*}{$\Delta$ duty $_{o k} \times \mathbf{R C A}$} & $1.747^{* * *}$ & & $1.763^{* * *}$ & $0.033^{* *}$ & & $0.033^{* *}$ & $0.042^{* *}$ & & $0.041^{* *}$ \\
\hline & $(0.350)$ & & $(0.355)$ & $(0.015)$ & & $(0.015)$ & $(0.018)$ & & $(0.018)$ \\
\hline \multirow[t]{2}{*}{$\Delta$ duty $_{e k}$} & & 0.625 & 0.891 & & -0.026 & -0.022 & & 0.044 & 0.042 \\
\hline & & $(0.476)$ & $(0.665)$ & & $(0.043)$ & $(0.052)$ & & $(0.029)$ & $(0.032)$ \\
\hline \multirow{2}{*}{$\Delta$ duty $_{e k} \times \mathbf{R C A}$} & & & -0.447 & & & -0.010 & & & -0.000 \\
\hline & & & $(0.624)$ & & & $(0.038)$ & & & $(0.061)$ \\
\hline \multirow[t]{2}{*}{$\mathrm{RCA}$} & $-0.153^{* *}$ & $0.124^{* * *}$ & $-0.158^{* *}$ & $-0.007^{* * *}$ & -0.002 & $-0.007^{* * *}$ & $-0.007^{*}$ & 0.000 & $-0.006^{*}$ \\
\hline & $(0.062)$ & $(0.046)$ & $(0.064)$ & $(0.003)$ & $(0.001)$ & $(0.003)$ & $(0.003)$ & $(0.002)$ & $(0.003)$ \\
\hline \multirow[t]{2}{*}{ TFP } & $0.037^{*}$ & $0.037^{*}$ & $0.036^{*}$ & $0.011^{* * *}$ & $0.011^{* * *}$ & $0.011^{* * *}$ & 0.002 & 0.003 & 0.002 \\
\hline & $(0.020)$ & $(0.020)$ & $(0.020)$ & $(0.004)$ & $(0.004)$ & $(0.004)$ & $(0.004)$ & $(0.004)$ & $(0.004)$ \\
\hline \multirow[t]{2}{*}{$\log (\mathrm{Empl})$} & $0.300^{* * *}$ & $0.298^{* * *}$ & $0.300^{* * *}$ & $-0.003^{* * *}$ & $-0.003^{* * *}$ & $-0.003^{* * *}$ & $-0.005^{* * *}$ & $-0.005^{* * *}$ & $-0.005^{* * *}$ \\
\hline & $(0.019)$ & $(0.019)$ & $(0.019)$ & $(0.001)$ & $(0.001)$ & $(0.001)$ & $(0.001)$ & $(0.001)$ & $(0.001)$ \\
\hline \multirow[t]{2}{*}{$\log (\mathrm{K} / \mathrm{L})$} & 0.026 & 0.025 & 0.026 & -0.000 & 0.000 & -0.000 & $0.007^{* * *}$ & $0.007^{* * *}$ & $0.007 * * *$ \\
\hline & $(0.018)$ & $(0.018)$ & $(0.018)$ & $(0.002)$ & $(0.002)$ & $(0.002)$ & $(0.002)$ & $(0.002)$ & $(0.002)$ \\
\hline \multirow[t]{2}{*}{$\log ($ Wage $)$} & $0.295^{* * *}$ & $0.293^{* * *}$ & $0.295^{* * *}$ & -0.009 & $-0.009^{*}$ & -0.009 & -0.000 & -0.001 & -0.000 \\
\hline & $(0.025)$ & $(0.026)$ & $(0.025)$ & $(0.006)$ & $(0.006)$ & $(0.006)$ & $(0.007)$ & $(0.007)$ & $(0.007)$ \\
\hline Year fixed effect & Yes & Yes & Yes & Yes & Yes & Yes & Yes & Yes & Yes \\
\hline Industry fixed effect & Yes & Yes & Yes & Yes & Yes & Yes & Yes & Yes & Yes \\
\hline Observations & 370102 & 370102 & 370102 & 2065 & 2065 & 2065 & 2065 & 2065 & 2065 \\
\hline Log likelihood & -79192 & -79346 & -79187 & & & & & & \\
\hline R-squared & & & & 0.066 & 0.065 & 0.066 & 0.064 & 0.063 & 0.065 \\
\hline \multicolumn{10}{|c|}{ Note: ${ }^{* * *}$ Significant at the $1 \%$ level; ${ }^{* *}$ Significant at the $5 \%$ level; ${ }^{*}$ Significant at the $10 \%$ level. } \\
\hline & & & & & & & & & \\
\hline
\end{tabular}

\section{More Robustness Checks}

In this section, we use estimation Method 1: input and output tariffs as measures of imported-input tariff and imported-output tariffs and report the results based on the index $\mathrm{RCA}_{1}$. In some tables, we also report the results based on the $\log$ rank of the index $\mathrm{RCA}_{1}$. For other indexes, the results are 
qualitatively the same. ${ }^{31}$

\subsection{Long-run Effect}

Our main results are based on one-year difference, i.e. the change is between $t$ and $t+1$. In Table 5 , we report the impacts on the LHS variables based on two-year difference, three-year difference and four-year difference. Here, we only report the results based on the index $\mathrm{RCA}_{1}$. For other indexes, the results are qualitatively the same. Columns 1-3 correspond to the probability of exporting; columns 4-6 corresponds to the change in fraction of exporting firms; columns 7-9 corresponds to the change in share of export revenue. The coefficients of the interaction of input tariff change and RCA are significantly negative in all columns. Thus, the robustness checks further support our Propositions 2-4.

\footnotetext{
${ }^{31}$ If we use the imported intermediated-good tariff and imported final-good tariff built on the merged data to do robust check, our results still hold qualitatively. The results are available upon request.
} 


\begin{tabular}{|c|c|c|c|c|c|c|c|c|c|}
\hline \multicolumn{10}{|c|}{ Table 5: Long-run Effect } \\
\hline \multirow[b]{2}{*}{ Regressor } & \multicolumn{3}{|c|}{ The probability of entry } & \multicolumn{3}{|c|}{ Change in export firms ratio } & \multicolumn{3}{|c|}{ Change in export revenue ratio } \\
\hline & Logit & Logit & Logit & OLS & OLS & OLS & OLS & OLS & OLS \\
\hline & (1) & (2) & (3) & (4) & (5) & (6) & (7) & (8) & (9) \\
\hline Year-difference & $2-\mathrm{yr}$ & $3-\mathrm{yr}$ & $4-\mathrm{yr}$ & $2-\mathrm{yr}$ & $3-\mathrm{yr}$ & $4-\mathrm{yr}$ & $2-\mathrm{yr}$ & $3-\mathrm{yr}$ & $4-\mathrm{yr}$ \\
\hline \multirow[t]{2}{*}{$\Delta$ duty $_{i k}$} & $2.448^{* *}$ & $2.322^{* *}$ & 1.175 & -0.099 & -0.057 & -0.116 & -0.049 & 0.055 & 0.095 \\
\hline & $(1.047)$ & $(1.039)$ & $(0.828)$ & $(0.075)$ & $(0.071)$ & $(0.081)$ & $(0.073)$ & $(0.082)$ & $(0.068)$ \\
\hline \multirow[t]{2}{*}{$\Delta$ duty $_{i k} \times \mathbf{R C A}$} & $-1.578^{* * *}$ & $-1.732^{* * *}$ & $-0.898^{* *}$ & $-0.064^{*}$ & $-0.101^{* * *}$ & $-0.072^{*}$ & $-0.072^{* *}$ & $-0.114^{* * *}$ & $-0.097^{* *}$ \\
\hline & $(0.352)$ & $(0.382)$ & $(0.369)$ & $(0.034)$ & $(0.030)$ & $(0.041)$ & $(0.032)$ & $(0.041)$ & $(0.046)$ \\
\hline \multirow[t]{2}{*}{$\Delta$ duty $_{\text {ok }}$} & -2.692 & -1.994 & -3.060 & $-0.288^{*}$ & $-0.309^{*}$ & -0.290 & -0.156 & $-0.312^{* *}$ & $-0.356^{* *}$ \\
\hline & $(2.871)$ & $(2.847)$ & $(2.768)$ & $(0.156)$ & $(0.165)$ & $(0.182)$ & $(0.141)$ & $(0.151)$ & $(0.162)$ \\
\hline \multirow[t]{2}{*}{$\mathrm{RCA}$} & $0.127^{* * *}$ & $0.143^{* * *}$ & $0.149^{* * *}$ & -0.003 & -0.002 & -0.006 & 0.002 & 0.005 & 0.002 \\
\hline & $(0.045)$ & $(0.047)$ & $(0.051)$ & $(0.003)$ & $(0.005)$ & $(0.006)$ & $(0.003)$ & $(0.005)$ & $(0.007)$ \\
\hline \multirow[t]{2}{*}{ TFP } & $0.078^{* * *}$ & $0.108^{* * *}$ & $0.128^{* * *}$ & $0.015^{* *}$ & $0.024^{* *}$ & $0.027^{*}$ & 0.006 & 0.007 & 0.003 \\
\hline & $(0.023)$ & $(0.024)$ & $(0.028)$ & $(0.006)$ & $(0.011)$ & $(0.015)$ & $(0.007)$ & $(0.010)$ & $(0.017)$ \\
\hline \multirow[t]{2}{*}{$\log (\mathrm{Empl})$} & $0.288^{* * *}$ & $0.280^{* * *}$ & $0.258^{* * *}$ & $-0.007^{* * *}$ & $-0.013^{* * *}$ & $-0.012^{* * *}$ & $-0.011^{* * *}$ & $-0.017^{* * *}$ & $-0.021^{* * *}$ \\
\hline & $(0.019)$ & $(0.022)$ & $(0.024)$ & $(0.002)$ & $(0.003)$ & $(0.004)$ & $(0.002)$ & $(0.003)$ & $(0.004)$ \\
\hline \multirow[t]{2}{*}{$\log (\mathrm{K} / \mathrm{L})$} & $0.059^{* * *}$ & $0.093^{* * *}$ & $0.096^{* * *}$ & 0.003 & -0.003 & -0.006 & $0.012^{* * *}$ & $0.017^{* * *}$ & $0.021^{* * *}$ \\
\hline & $(0.021)$ & $(0.024)$ & $(0.023)$ & $(0.004)$ & $(0.006)$ & $(0.007)$ & $(0.004)$ & $(0.006)$ & $(0.007)$ \\
\hline \multirow[t]{2}{*}{$\log$ (Wage) } & $0.240^{* * *}$ & $0.236^{* * *}$ & $0.185^{* * *}$ & $-0.020^{*}$ & $-0.029 *$ & -0.028 & -0.002 & -0.003 & 0.001 \\
\hline & $(0.029)$ & $(0.031)$ & $(0.037)$ & $(0.011)$ & $(0.016)$ & $(0.020)$ & $(0.010)$ & $(0.016)$ & $(0.022)$ \\
\hline Year fixed effect & Yes & Yes & Yes & Yes & Yes & Yes & Yes & Yes & Yes \\
\hline Industry fixed effect & Yes & Yes & Yes & Yes & Yes & Yes & Yes & Yes & Yes \\
\hline Observations & 224581 & 116715 & 63646 & 1652 & 1239 & 826 & 1652 & 1239 & 826 \\
\hline Log likelihood & -60429 & -37458 & -22216 & & & & & & \\
\hline R-squared & & & & 0.098 & 0.142 & 0.161 & 0.127 & 0.184 & 0.234 \\
\hline \multicolumn{10}{|c|}{ Note: ${ }^{* * *}$ Significant at the $1 \%$ level; ${ }^{* *}$ Significant at the $5 \%$ level; ${ }^{*}$ Significant at the $10 \%$ level. } \\
\hline & & & & & & & & & \\
\hline
\end{tabular}

\subsection{Processing and Ordinary Trade}

We may want to focus on only non-processing trade firms in our empirical estimation, as tariff reduction in imported intermediate goods should have little impact on the processing-trade firms, whose imported inputs were tariff-free. One can only distinguish between processing and ordinary trade when using the customs data set. To carry out this robustness check, we use the merged data of the firm-level manufacturing survey data set and the customs data set. Based on this merged data set, we can distinguish among firms that engage in processing trade, ordinary trade and hybrid trade. (Some firms engage in both processing trade and ordinary trade, and we call them hybrid-trade firms.) Thus, we 
drop the processing-trade and hybrid-trade firms from our sample and re-run our regressions. ${ }^{32}$ Table 6 shows that our results continue to hold when we eliminate the processing-trade and hybrid-trade firms. In Table 6, columns 1 and 4 correspond to the probability of exporting; columns 2 and 5 correspond to the change in fraction of exporting firms; columns 3 and 6 corresponds to the change in share of export revenue. In columns $1-3$, use $\mathrm{RCA}_{1}$ to proxy for revealed comparative advantage. In columns 4-6, we use the $\log$ rank of $\mathrm{RCA}_{1}$ as the proxy.

\begin{tabular}{|c|c|c|c|c|c|c|}
\hline \multicolumn{7}{|c|}{ Table 6: Eliminating processing trade and hybrid trade firms } \\
\hline & \multicolumn{3}{|c|}{$\mathrm{RCA}_{1}$} & \multicolumn{3}{|c|}{$\operatorname{Rank}_{R C A_{1}}$} \\
\hline & Prob & Frac & Share & Prob & Frac & Share \\
\hline \multirow[t]{2}{*}{ Regressor } & Logit & OLS & OLS & Logit & OLS & OLS \\
\hline & (1) & $(2)$ & $(3)$ & $(4)$ & $(5)$ & $(6)$ \\
\hline \multirow[t]{2}{*}{$\Delta$ duty $_{i k}$} & $2.746^{* *}$ & 0.032 & 0.047 & 11.783 & 0.153 & $0.322^{* * *}$ \\
\hline & $(1.152)$ & $(0.057)$ & $(0.050)$ & $(7.487)$ & $(0.100)$ & $(0.120)$ \\
\hline \multirow[t]{2}{*}{$\Delta$ duty $_{i k} \times \mathbf{R C A}$} & $-1.753^{* * *}$ & $-0.117^{* * *}$ & $-0.122^{* * *}$ & $-3.442^{*}$ & $-0.086^{* * *}$ & $-0.136^{* * *}$ \\
\hline & $(0.296)$ & $(0.039)$ & $(0.036)$ & $(1.886)$ & $(0.032)$ & $(0.043)$ \\
\hline \multirow[t]{2}{*}{$\Delta$ duty $_{o k}$} & -2.249 & -0.065 & -0.167 & -3.784 & -0.003 & -0.189 \\
\hline & $(3.344)$ & $(0.114)$ & $(0.119)$ & $(4.031)$ & $(0.130)$ & $(0.142)$ \\
\hline \multirow[t]{2}{*}{ RCA } & $0.124^{* * *}$ & -0.001 & -0.001 & $0.312^{* * *}$ & -0.001 & 0.000 \\
\hline & $(0.046)$ & $(0.001)$ & $(0.002)$ & $(0.072)$ & $(0.002)$ & $(0.001)$ \\
\hline \multirow[t]{2}{*}{ TFP } & $0.039^{* *}$ & $0.013^{* * *}$ & 0.000 & $0.040^{* *}$ & $0.014^{* * *}$ & 0.001 \\
\hline & $(0.020)$ & $(0.003)$ & $(0.004)$ & $(0.019)$ & $(0.003)$ & $(0.005)$ \\
\hline \multirow[t]{2}{*}{$\log (\mathrm{Empl})$} & $0.264^{* * *}$ & $-0.003^{* * *}$ & $-0.004^{* * *}$ & $0.266^{* * *}$ & $-0.003^{* * *}$ & $-0.004^{* * *}$ \\
\hline & $(0.020)$ & $(0.001)$ & $(0.001)$ & $(0.020)$ & $(0.001)$ & $(0.001)$ \\
\hline \multirow[t]{2}{*}{$\log (\mathrm{K} / \mathrm{L})$} & 0.006 & -0.001 & $0.005^{*}$ & 0.010 & -0.002 & $0.005^{*}$ \\
\hline & $(0.018)$ & $(0.003)$ & $(0.003)$ & $(0.018)$ & $(0.003)$ & $(0.003)$ \\
\hline \multirow[t]{2}{*}{$\log ($ Wage $)$} & $0.247^{* * *}$ & $-0.009^{*}$ & 0.002 & $0.249^{* * *}$ & $-0.009 *$ & 0.002 \\
\hline & $(0.027)$ & $(0.005)$ & $(0.007)$ & $(0.027)$ & $(0.005)$ & $(0.007)$ \\
\hline Year fixed effect & Yes & Yes & Yes & Yes & Yes & Yes \\
\hline Industry fixed effect & Yes & Yes & Yes & Yes & Yes & Yes \\
\hline Observations & 364038 & 2065 & 2065 & 364038 & 2065 & 2065 \\
\hline Log Likelihood & -72670 & & & -72579 & & \\
\hline R-squared & & 0.057 & 0.059 & & 0.052 & 0.056 \\
\hline \multicolumn{7}{|c|}{ Note: ${ }^{* * *}$ Significant at the $1 \%$ level; ${ }^{* *}$ Significant at the $5 \%$ level; ${ }^{*}$ Significant at the $10 \%$ level. } \\
\hline Robu & & 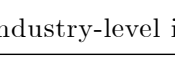 & aren & & & \\
\hline
\end{tabular}

\footnotetext{
${ }^{32}$ When we use the merged data, many observations would be lost due to mismatch and only the large firms are left. As a results, the changes in the fraction of exporting firms and changes in the share of export revenue that we compute based on the merged data may not reflect a representative picture of the impacts of changes in imported-inputs and importedoutputs. It would not be proper to use the entire merged data set to test propositions 2-4 since these propositions are about the resource reallocation across sectors, which highly depend on the behavior of small firms. Therefore, we purged the processing-trade and hybrid-trade firms from the merged data set before we re-test our propositions 2-4.
} 


\subsection{RCA based on final goods only}

One might argue that it is more appropriate to use only the data on trade values of final goods to calculate the revealed comparative advantage index. As a robustness check, we eliminate intermediate goods and capital goods which are used as production inputs from the bilateral trade flow data from CEPII, based on the Broad Economic Categories (BEC) classification. Then we recalculate the revealed comparative advantage index. ${ }^{33}$ Table 7 shows that our results continue to hold after such a modification. In Table 7, columns 1 and 4 correspond to the probability of exporting; columns 2 and 5 corresponds to the change in fraction of exporting firms; columns 3 and 6 corresponds to the change in share of export revenue. In columns $1-3$, we use $\mathrm{RCA}_{1}$ to proxy for revealed comparative advantage. In columns 4-6, we use the $\log$ rank of $\mathrm{RCA}_{1}$ as the proxy.

\footnotetext{
${ }^{33}$ If we only delete the intermediate goods when recalculating the revealed comparative advantage, the results would be similar.
} 


\begin{tabular}{|c|c|c|c|c|c|c|}
\hline \multicolumn{7}{|c|}{ Table 7: RCA based on final goods only } \\
\hline \multirow[t]{2}{*}{ RCA index } & \multicolumn{3}{|c|}{$\mathrm{RCA}_{1}$} & \multicolumn{3}{|c|}{$\operatorname{Rank}_{R C A_{1}}$} \\
\hline & Prob & Frac & Share & Prob & Frac & Share \\
\hline \multirow[t]{2}{*}{ Regressor } & Logit & OLS & OLS & Logit & OLS & OLS \\
\hline & (1) & $(2)$ & $(3)$ & $(4)$ & $(5)$ & $(6)$ \\
\hline \multirow[t]{2}{*}{$\Delta$ duty $_{i k}$} & 1.996 & -0.023 & 0.021 & -1.134 & -0.015 & 0.026 \\
\hline & $(1.411)$ & $(0.044)$ & $(0.039)$ & $(1.667)$ & $(0.046)$ & $(0.049)$ \\
\hline \multirow[t]{2}{*}{$\Delta$ duty $_{i k} \times \mathbf{R C A}$} & $-1.141^{* *}$ & $-0.090^{* * *}$ & $-0.115^{* * *}$ & -0.095 & $-0.052^{* * *}$ & $-0.068^{* *}$ \\
\hline & $(0.489)$ & $(0.029)$ & $(0.039)$ & $(0.528)$ & $(0.018)$ & $(0.027)$ \\
\hline \multirow[t]{2}{*}{$\Delta$ duty $_{o k}$} & 5.461 & -0.054 & -0.158 & 5.303 & 0.042 & -0.105 \\
\hline & $(3.496)$ & $(0.114)$ & $(0.121)$ & $(3.698)$ & $(0.130)$ & $(0.142)$ \\
\hline \multirow[t]{2}{*}{$\mathrm{RCA}$} & 0.074 & -0.002 & -0.000 & $0.446^{* * *}$ & -0.004 & 0.002 \\
\hline & $(0.056)$ & $(0.002)$ & $(0.002)$ & $(0.110)$ & $(0.003)$ & $(0.003)$ \\
\hline \multirow[t]{2}{*}{ TFP } & 0.028 & $0.010^{* * *}$ & 0.002 & 0.030 & $0.010^{* *}$ & 0.003 \\
\hline & $(0.021)$ & $(0.004)$ & $(0.005)$ & $(0.020)$ & $(0.004)$ & $(0.005)$ \\
\hline \multirow[t]{2}{*}{$\log (\mathrm{Empl})$} & $0.312^{* * *}$ & $-0.004^{* * *}$ & $-0.005^{* * *}$ & $0.318^{* * *}$ & $-0.004^{* * *}$ & $-0.006^{* * *}$ \\
\hline & $(0.019)$ & $(0.001)$ & $(0.001)$ & $(0.019)$ & $(0.001)$ & $(0.001)$ \\
\hline \multirow[t]{2}{*}{$\log (\mathrm{K} / \mathrm{L})$} & 0.020 & 0.001 & $0.007^{* * *}$ & 0.025 & 0.000 & $0.007 * * *$ \\
\hline & $(0.019)$ & $(0.003)$ & $(0.002)$ & $(0.019)$ & $(0.003)$ & $(0.002)$ \\
\hline \multirow[t]{2}{*}{$\log ($ Wage $)$} & $0.296^{* * *}$ & -0.009 & 0.001 & $0.294^{* * *}$ & -0.009 & 0.001 \\
\hline & $(0.026)$ & $(0.006)$ & $(0.008)$ & $(0.026)$ & $(0.006)$ & $(0.008)$ \\
\hline Year fixed effect & Yes & Yes & Yes & Yes & Yes & Yes \\
\hline Industry fixed effect & Yes & Yes & Yes & Yes & Yes & Yes \\
\hline Observations & 297262 & 1800 & 1800 & 297262 & 1800 & 1800 \\
\hline Log Likelihood & -68966 & & & -68807 & & \\
\hline R-squared & & 0.071 & 0.064 & & 0.068 & 0.061 \\
\hline \multicolumn{7}{|c|}{ Note: ${ }^{* * *}$ Significant at the $1 \%$ level; ${ }^{* *}$ Significant at the $5 \%$ level; ${ }^{*}$ Significant at the $10 \%$ level. } \\
\hline & - & - & 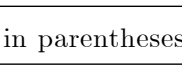 & & & \\
\hline
\end{tabular}

\subsection{Sensitivity to Currency Appreciation and Multi-Fibre Arrangement}

Our main results show the effect of imported-input trade liberalization on exporting behavior in China. It should be noted that prices of imported goods were mostly denominated in US dollars. One may be concerned that the appreciation of Renminbi (Chinese currency, hereafter RMB) would affect firms' export behavior. It is possible that a stronger RMB reduces firms' costs of purchasing imported inputs with the local currency, and hence improves firms' competitive in the foreign market. To test the sensitivity of our results to RMB appreciation, we only use the data during the period before the appreciation to test propositions 2-4. As RMB appreciated in late 2005, we dropped data for 2005 and 2006, and use the sample in the years 2001-2004 to test our propositions. We use RCA 1 to proxy 
for revealed comparative advantage. Column 1-3 in Table 8 reports the results and all coefficients on $\Delta$ duty $_{i k} \times$ RCA are significantly negative, consistent with the prediction of the theory. In Table 8 , columns 1 and 4 correspond to the probability of exporting; columns 2 and 5 corresponds to the change in fraction of exporting firms; columns 3 and 6 corresponds to the change in share of export revenue.

In column 4-6, we test the sensitivity of our results to Multi-Fibre Arrangement (MFA). In order to do this, we delete the textile sectors. ${ }^{34}$ The rationale behind this robustness check is that under the MFA, developed countries were allowed to impose quotas on the amount of textile and garments imported from the developing countries. Before the expiration of the MFA on January 1 2005, the quotas served as higher trade barriers compared to the tariff rates in these textile sectors, and the tariff-equivalent measures of theses quotas are not easy to obtain and might not be precise. In order to prevent the bias caused by the MFA, we delete the textile sectors, re-run the regressions and obtain the results in columns 4 to 6 of Table 8 . All coefficients on $\Delta$ duty $_{i k} \times \mathrm{RCA}$ are negative and mostly significant and consistent with the prediction of the theory.

\footnotetext{
${ }^{34}$ We delete sectors 17, 18 and 19. Sector 17 is Manufacture of Textile; sector 18 is Manufacture of Textile Wearing Apparel, Footware, and Caps; sector 19 is Manufacture of Leather, Fur, Feather and Related Products.
} 


\begin{tabular}{|c|c|c|c|c|c|c|}
\hline \multicolumn{7}{|c|}{ Table 8: Sensitivity to Currency Appreciation and Multi-fibre Agreement } \\
\hline & \multicolumn{3}{|c|}{ No Currency Appreciation } & \multicolumn{3}{|c|}{ Without Multi-fibre Agreement } \\
\hline & Prob & Frac & Share & Prob & Frac & Share \\
\hline \multirow[t]{2}{*}{ Regressor } & Logit & OLS & OLS & Logit & OLS & OLS \\
\hline & (1) & $(2)$ & $(3)$ & $(4)$ & $(5)$ & (6) \\
\hline \multirow[t]{2}{*}{$\Delta$ duty $_{i k}$} & $2.840^{* *}$ & -0.002 & -0.011 & $2.551^{*}$ & -0.007 & 0.011 \\
\hline & $(1.115)$ & $(0.051)$ & $(0.050)$ & $(1.435)$ & $(0.050)$ & $(0.037)$ \\
\hline \multirow[t]{2}{*}{$\Delta$ duty $_{i k} \times \mathbf{R C A}$} & $-1.730 * * *$ & $-0.084^{* *}$ & $-0.080^{* *}$ & $-2.487^{* * *}$ & -0.124 & $-0.130 * *$ \\
\hline & $(0.312)$ & $(0.033)$ & $(0.037)$ & $(0.483)$ & $(0.083)$ & $(0.055)$ \\
\hline \multirow[t]{2}{*}{$\Delta$ duty $_{o k}$} & -1.604 & -0.112 & -0.109 & -0.795 & -0.067 & -0.111 \\
\hline & $(3.724)$ & $(0.116)$ & $(0.120)$ & $(3.525)$ & $(0.110)$ & $(0.100)$ \\
\hline \multirow[t]{2}{*}{$\mathrm{RCA}$} & $0.134^{* * *}$ & -0.001 & 0.001 & $0.126^{* *}$ & -0.001 & 0.000 \\
\hline & $(0.044)$ & $(0.002)$ & $(0.002)$ & $(0.061)$ & $(0.002)$ & $(0.002)$ \\
\hline \multirow[t]{2}{*}{ TFP } & $0.074^{* * *}$ & $0.008^{* *}$ & 0.001 & $0.062^{* * *}$ & $0.012^{* * *}$ & 0.003 \\
\hline & $(0.021)$ & $(0.004)$ & $(0.005)$ & $(0.017)$ & $(0.004)$ & $(0.004)$ \\
\hline \multirow[t]{2}{*}{$\log (\mathrm{Empl})$} & $0.284^{* * *}$ & $-0.004^{* * *}$ & $-0.005^{* * *}$ & $0.302^{* * *}$ & $-0.003^{* * *}$ & $-0.005^{* * *}$ \\
\hline & $(0.019)$ & $(0.001)$ & $(0.001)$ & $(0.022)$ & $(0.001)$ & $(0.001)$ \\
\hline \multirow[t]{2}{*}{$\log (\mathrm{K} / \mathrm{L})$} & 0.029 & 0.001 & $0.006^{* *}$ & $0.052^{* * *}$ & 0.000 & $0.008^{* * *}$ \\
\hline & $(0.019)$ & $(0.003)$ & $(0.002)$ & $(0.018)$ & $(0.003)$ & $(0.002)$ \\
\hline \multirow[t]{2}{*}{$\log$ (Wage) } & $0.240^{* * *}$ & -0.009 & -0.003 & $0.287^{* * *}$ & -0.009 & -0.002 \\
\hline & $(0.027)$ & $(0.006)$ & $(0.008)$ & $(0.029)$ & $(0.006)$ & $(0.007)$ \\
\hline Year fixed effect & Yes & Yes & Yes & Yes & Yes & Yes \\
\hline Industry fixed effect & Yes & Yes & Yes & Yes & Yes & Yes \\
\hline Observations & 270407 & 1652 & 1652 & 327495 & 1900 & 1900 \\
\hline Log Likelihood & -60549 & & & -64463 & & \\
\hline R-squared & & .0358 & .0503 & & .0505 & .0524 \\
\hline \multicolumn{7}{|c|}{ Note: ${ }^{* * *}$ Significant at the $1 \%$ level; ${ }^{* *}$ Significant at the $5 \%$ level; ${ }^{*}$ Significant at the $10 \%$ level. } \\
\hline
\end{tabular}

\section{Conclusion}

We have built a trade model to capture the special characteristics of the Chinese economy, namely that Chinese firms imported mostly intermediate goods and exported mostly final goods in the year just before and some years just after China's accession to the WTO in 2001. We use this as a natural experiment to test how final-goods producers' entry, exit, output and exporting decisions respond to trade liberalization in imported intermediate goods, and how they respond differently across sectors.

Our theoretical model incorporates Ricardian comparative advantage into a multi-sector, twocountry version of Melitz's (2003) monopolistic competition model with heterogeneous final-good firms, which produce using intermediate goods and labor. We use the model to explain how comparative 
advantage, economies of scale and firm heterogeneity interact to give rise to inter-industry trade and intra-industry trade. We then analyze the effects of imported-input trade liberalization in the intraindustry trade sectors. We decompose the total effect of imported-input trade liberalization into those caused by inter-sectoral resource allocation (which we call IRA effect) and by the within-sector selection of firms according to productivity (which we call Melitz selection effect).

We argue that it is the IRA effect that drives the differential impacts of imported-input trade liberalization in different sectors on variables such as the probability of entry into export market, fraction of firms that export and the share of export revenue. We test our hypotheses using Chinese firm-level data for the years just after China's accession to WTO in 2001. The results generally support our hypotheses.

Our theory predicts that imported-output trade liberalization leads to opposite effects on firms' exporting behaviors compared with imported-input trade liberalization. We also verify this prediction in the empirical estimation of the model. 


\section{Appendixes}

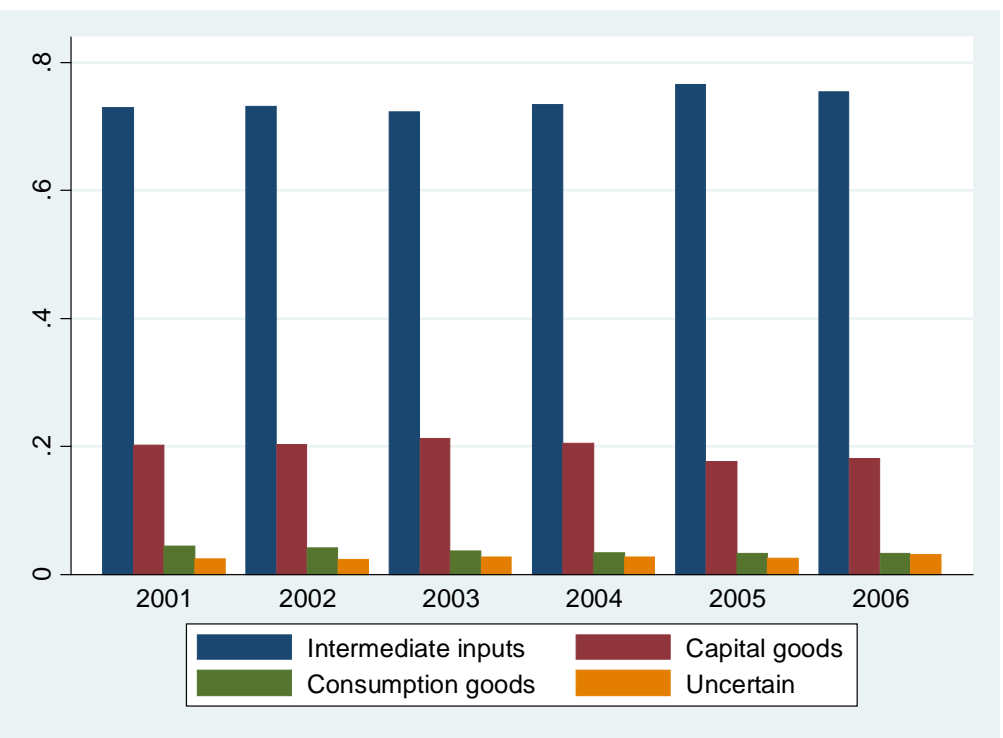

Figure A1. The percentages of types of goods imported by

China by year.

\section{A Solving the System}

In this appendix, we will show how to solve the model for the sectors in which both countries produce. In other words, we solve for $\left(\bar{\varphi}_{d k}, \bar{\varphi}_{d k}^{*}, \bar{\varphi}_{x k}, \bar{\varphi}_{x k}^{*}, \theta_{d k}, \theta_{d k}^{*}\right)$ from the system constituted of the four ZCP conditions and two FE conditions. Combining the two ZCP conditions for firms serving the Home market, (15) and (18), we have

$$
\frac{\bar{\varphi}_{x k}^{*}}{\bar{\varphi}_{d k}}=B_{3 k}^{\frac{1}{\gamma}} a_{k}\left(\frac{B_{2 k} f_{x}}{f}\right)^{\frac{1}{\gamma}}
$$

Similarly, combining ZCP for firms serving Foreign's market, (16) and (17), we can get

$$
\frac{\bar{\varphi}_{x k}}{\bar{\varphi}_{d k}^{*}}=\frac{1}{B_{3 k}^{\frac{1}{\gamma}} a_{k}}\left(\frac{B_{1 k} f_{x}}{f}\right)^{\frac{1}{\gamma}}
$$


The ZCP conditions are given by

$$
\begin{aligned}
& r_{d k}\left(\bar{\varphi}_{d k}\right)=\beta_{k} L\left[P_{k} \frac{\widetilde{\rho} A_{k}}{\left(c_{k}\right)^{\mu}} \bar{\varphi}_{d k}\right]^{\sigma-1}=\sigma f \\
& r_{d k}^{*}\left(\bar{\varphi}_{d k}^{*}\right)=\beta_{k} L^{*}\left[P_{k}^{*} \frac{\widetilde{\rho} A_{k}^{*}}{\left(c_{k}^{*}\right)^{\mu}} \bar{\varphi}_{d k}^{*}\right]^{\sigma-1}=\sigma f \\
& r_{x k}\left(\bar{\varphi}_{x k}\right)=\beta_{k} L^{*}\left[\frac{P_{k}^{*}}{\tau_{x k}} \frac{\widetilde{\rho} A_{k}}{\left(c_{k}\right)^{\mu}} \bar{\varphi}_{x k}\right]^{\sigma-1}=\sigma f_{x} \\
& r_{x k}^{*}\left(\bar{\varphi}_{x k}^{*}\right)=\beta_{k} L\left[\frac{P_{k}}{\tau_{x k}^{*}} \frac{\widetilde{\rho} A_{k}^{*}}{\left(c_{k}^{*}\right)^{\mu}} \bar{\varphi}_{x k}^{*}\right]^{\sigma-1}=\sigma f_{x}
\end{aligned}
$$

Let $\widetilde{\pi}_{k}$ and $\widetilde{\pi}_{k}^{*}$ denote the average profit flow of a surviving firm in sector $k$ in Home and Foreign respectively. It can be easily shown that ${ }^{35}$

$$
\begin{aligned}
& \widetilde{\pi}_{k}=\pi_{d k}\left(\widetilde{\varphi}_{d k}\right)+\left[\frac{1-G\left(\bar{\varphi}_{x k}\right)}{1-G\left(\bar{\varphi}_{d k}\right)}\right] \pi_{x k}\left(\widetilde{\varphi}_{x k}\right)=\frac{\sigma-1}{\gamma-\sigma+1}\left[f+\left(\frac{\bar{\varphi}_{d k}}{\bar{\varphi}_{x k}}\right)^{\gamma} f_{x}\right] \\
& \tilde{\pi}_{k}^{*}=\pi_{d k}^{*}\left(\widetilde{\varphi}_{d k}^{*}\right)+\left[\frac{1-G\left(\bar{\varphi}_{x k}^{*}\right)}{1-G\left(\bar{\varphi}_{d k}^{*}\right)}\right] \pi_{x k}^{*}\left(\widetilde{\varphi}_{x k}^{*}\right)=\frac{\sigma-1}{\gamma-\sigma+1}\left[f+\left(\frac{\bar{\varphi}_{d k}^{*}}{\bar{\varphi}_{x k}^{*}}\right)^{\gamma} f_{x}\right] .
\end{aligned}
$$

A firm will enter if its expected post-entry profit is above the fixed cost of entry. The free entry (FE) condition determines that the entry cost is equal to the post-entry expected economic profits. Hence, the FE conditions for Home and Foreign are, respectively

$$
\begin{aligned}
& f_{e}=\left[1-G\left(\bar{\varphi}_{d k}\right)\right] \widetilde{\pi}_{k}=\left(\frac{\sigma-1}{\gamma-\sigma+1}\right)\left[f \cdot\left(\bar{\varphi}_{d k}\right)^{-\gamma}+f_{x} \cdot\left(\bar{\varphi}_{x k}\right)^{-\gamma}\right] \\
& f_{e}=\left[1-G\left(\bar{\varphi}_{d k}^{*}\right)\right] \tilde{\pi}_{k}^{*}=\left(\frac{\sigma-1}{\gamma-\sigma+1}\right)\left[f \cdot\left(\bar{\varphi}_{d k}^{*}\right)^{-\gamma}+f_{x} \cdot\left(\bar{\varphi}_{x k}^{*}\right)^{-\gamma}\right]
\end{aligned}
$$

Equations (13), (14), and the FE conditions (19) and (20) now form a system of four equations and four unknowns, $\bar{\varphi}_{d k}, \bar{\varphi}_{x k}, \bar{\varphi}_{d k}^{*}$ and $\bar{\varphi}_{x k}^{*}$. Solving, we obtain (5), (6), (7) and (8).

Then, recall that the aggregate price indexes for final goods are given by $P_{k}=\left(\theta_{k}\right)^{\frac{1}{1-\sigma}} p_{d k}\left(\widetilde{\varphi}_{k}\right)$ and $P_{k}^{*}=\left(\theta_{k}^{*}\right)^{\frac{1}{1-\sigma}} p_{d k}^{*}\left(\widetilde{\varphi}_{k}^{*}\right)$. Substituting these price indexes into ZCP conditions (15) and (16), and, with the help of equations (2) and (3), we have

$$
\begin{aligned}
& \sigma f=\frac{\beta_{k} L}{\theta_{k}}\left(\frac{\bar{\varphi}_{d k}}{\widetilde{\varphi}_{k}}\right)^{\sigma-1}=\left(\frac{\gamma-\sigma+1}{\gamma}\right) \cdot \frac{\beta_{k} L}{\theta_{d k}+\theta_{x k}^{*} \frac{f_{x}}{f}} \\
& \sigma f=\frac{\beta_{k} L^{*}}{\theta_{k}^{*}}\left(\frac{\bar{\varphi}_{d k}^{*}}{\widetilde{\varphi}_{k}^{*}}\right)^{\sigma-1}=\left(\frac{\gamma-\sigma+1}{\gamma}\right) \cdot \frac{\beta_{k} L^{*}}{\theta_{d k}^{*}+\theta_{x k} \frac{f_{x}}{f}}
\end{aligned}
$$

\footnotetext{
${ }^{35} \widetilde{\pi}_{d k} \equiv \pi_{d k}\left(\widetilde{\varphi}_{d k}\right)=\frac{r_{d k}\left(\widetilde{\varphi}_{d k}\right)}{\sigma}-f=\frac{1}{\sigma}\left(\frac{\widetilde{\varphi}_{d k}}{\bar{\varphi}_{d k}}\right)^{\sigma-1} r_{d k}\left(\bar{\varphi}_{d k}\right)-f=f\left[\left(\frac{\widetilde{\varphi}_{d k}}{\bar{\varphi}_{d k}}\right)^{\sigma-1}-1\right]=f \cdot \frac{\sigma-1}{\gamma-\sigma+1}$. The third equality arises from the fact that $\left(\frac{\widetilde{\varphi}_{d k}}{\bar{\varphi}_{d k}}\right)^{\sigma-1}=\frac{r_{d k}\left(\widetilde{\varphi}_{d k}\right)}{r_{d k}\left(\bar{\varphi}_{d k}\right)}$. The fourth equality comes from the fact that $\sigma f=r_{d k}\left(\bar{\varphi}_{d k}\right)$, which is the ZCP condition above. The fifth equality comes from equation (4). Furthermore, $\tilde{\pi}_{x k}=f_{x}\left(\frac{\sigma-1}{\gamma-\sigma+1}\right)$ can be derived from similar steps as above by replacing the subscript " $d$ " by " $x$ " and the variable $f$ by $f_{x}$. Finally, note that $1-G(\varphi)=\varphi^{-\gamma}$.
} 
From the equilibrium productivity cutoffs (5) and (6) in both countries, we get

$$
\left(\frac{\bar{\varphi}_{d k}}{\bar{\varphi}_{d k}^{*}}\right)^{\gamma}=\frac{B_{1 k}}{B_{2 k}}\left[\frac{B_{2 k}-B_{3 k}^{-1}\left(a_{k}\right)^{-\gamma}}{B_{1 k}-B_{3 k}\left(a_{k}\right)^{\gamma}}\right]
$$

Therefore, the number of exporting firms in Home and Foreign are respectively:

$$
\begin{aligned}
& \theta_{x k}=\left(\frac{\bar{\varphi}_{d k}}{\bar{\varphi}_{x k}}\right)^{\gamma} \theta_{d k}=\left(a_{k} \frac{\bar{\varphi}_{d k}}{\bar{\varphi}_{d k}^{*}}\right)^{\gamma}\left(\frac{B_{3 k} f}{B_{1 k} f_{x}}\right) \theta_{d k} \\
& \theta_{x k}^{*}=\left(\frac{\bar{\varphi}_{d k}^{*}}{\bar{\varphi}_{x k}^{*}}\right)^{\gamma} \theta_{d k}^{*}=\left(\frac{\bar{\varphi}_{d k}^{*}}{a_{k} \bar{\varphi}_{d k}}\right)^{\gamma}\left(\frac{f}{B_{3 k} B_{2 k} f_{x}}\right) \theta_{d k}^{*}
\end{aligned}
$$

Equations (21), (22), (23), (24), (25) then imply (9) and (10).

$\theta_{x k}$ and $\theta_{x k}^{*}$ can be obtained by substituting (23), (9), (10) into (24) and (25) respectively. Table

\begin{tabular}{|c|c|c|c|c|}
\hline Sector type & Foreign-dominated & \multicolumn{2}{|l|}{ Two-way trade } & Home-dominated \\
\hline & $k<k_{1}$ & \multicolumn{2}{|l|}{$k_{1}<k<k_{2}$} & $k>k_{2}$ \\
\hline$\left(\bar{\varphi}_{d k}\right)^{\gamma}$ & $\varnothing$ & \multicolumn{2}{|l|}{\begin{tabular}{|c|c|}
$D_{1}$ & $\frac{B_{1 k}-B_{2 k}^{-1}}{B_{1 k}-B_{3 k}\left(a_{k}\right)^{\gamma}}$
\end{tabular}} & $D_{1} \frac{L+L^{*}}{L}$ \\
\hline$\left(\bar{\varphi}_{x k}\right)^{\gamma}$ & $\varnothing$ & $\frac{B_{2 k}-B_{1 k}^{-1}}{B_{2 k}-B_{3 k}^{-1}\left(a_{k}\right)^{-}}$ & $\frac{1}{B_{3 k}\left(a_{k}\right)^{\gamma}}\left(\frac{B_{1 k} f_{x}}{f}\right)$ & $D_{1} \frac{f_{x}}{f}\left(\frac{L+L^{*}}{L^{*}}\right)$ \\
\hline$\left(\bar{\varphi}_{d k}^{*}\right)^{\gamma}$ & $D_{1} \frac{L+L^{*}}{L^{*}}$ & $\frac{B_{2 k}-B_{1 k}^{-1}}{B_{2 k}-B_{3 k}^{-1}\left(a_{k}\right)^{-\gamma}}$ & & $\varnothing$ \\
\hline$\left(\bar{\varphi}_{x k}^{*}\right)^{\gamma}$ & $D_{1} \frac{f_{x}}{f} \frac{L+L^{*}}{L}$ & {$\left[\frac{B_{1 k}-B_{2 k}^{-1}}{B_{1 k}-B_{3 k}\left(a_{k}\right)^{\gamma}}\right]$} & $B_{3 k}\left(a_{k}\right)^{\gamma}\left(\frac{B_{2 k} f_{x}}{f}\right)$ & $\varnothing$ \\
\hline$\theta_{d k}$ & 0 & \multicolumn{2}{|c|}{$D_{2}(k)\left[\frac{B_{1 k} L-\frac{B_{1 k}-B_{3 k}\left(a_{k}\right)^{\prime}}{B_{2 k} B_{3 k}\left(a_{k}\right)^{\gamma}-1} L^{*}}{B_{1 k}-B_{2 k}^{-1}}\right]$} & $D_{2}(k) L$ \\
\hline$\theta_{x k}$ & 0 & \multicolumn{2}{|l|}{$\left(\frac{\bar{\varphi}_{d k}}{\bar{\varphi}_{x k}}\right)^{\gamma^{2}} \theta_{d k}$} & $D_{2}(k) \frac{f}{f_{x}} L^{*}$ \\
\hline$\theta_{d k}^{*}$ & $D_{2}(k) L^{*}$ & \multicolumn{2}{|c|}{$D_{2}(k)\left[\frac{B_{2 k} L^{*}-\frac{B_{2 k} B_{3 k}\left(a_{k}\right)^{\gamma}-1}{B_{1 k}-B_{3 k}\left(a_{k}\right)^{\gamma} L}}{B_{2 k}-B_{1 k}^{-1}}\right]$} & 0 \\
\hline$\theta_{x k}^{*}$ & $D_{2}(k) \frac{f}{f_{x}} L$ & \multicolumn{2}{|l|}{$\left(\frac{\bar{\varphi}_{d k}^{*}}{\bar{\varphi}_{x k}^{*}}\right)^{\gamma^{2}} \theta_{d k}^{*}$} & 0 \\
\hline$P_{k}$ & {$\left[D_{2}(k) \frac{f}{f_{x}} L\right]^{\frac{1}{1-\sigma}} \frac{\tau_{x k}^{*}\left(c_{c}^{*}\right)^{\mu}}{\tilde{\rho} A_{k}^{*} \widetilde{\varphi}_{x k}^{*}}$} & \multicolumn{2}{|l|}{$\left[D_{2}(k) L\right]^{\frac{1}{1-\sigma}} \frac{\left(c_{k}\right)^{\mu}}{\widetilde{\rho} A_{k} \widetilde{\varphi}_{d k}}$} & {$\left[D_{2}(k) L\right]^{\frac{1}{1-\sigma}} \frac{\left(c_{k}\right)^{\mu}}{\widetilde{\rho} A_{k} \widetilde{\varphi}_{d k}}$} \\
\hline$P_{k}^{*}$ & {$\left[D_{2}(k) L^{*}\right]^{\frac{1}{1-\sigma}} \frac{\left(c_{k}^{*}\right)^{\mu}}{\frac{\tilde{\rho} A_{k}^{*} \widetilde{\varphi}_{d k}^{*}}{2}}$} & \multicolumn{2}{|c|}{$\left[D_{2}(k) L^{*}\right]^{\frac{1}{1-\sigma}} \frac{\left(c_{k}^{*}\right)^{\mu}}{\tilde{\widetilde{\rho}} A_{k}^{*} \widetilde{\varphi}_{d k}^{*}}$} & {$\left[D_{2}(k) \frac{f}{f_{x}} L^{*}\right]^{\frac{1}{1-\sigma}} \frac{\tau_{x k}\left(c_{k}\right)^{\mu}}{\tilde{\rho} A_{k} \bar{\varphi}_{x k}}$} \\
\hline \multicolumn{5}{|c|}{$\begin{array}{l}D_{1}=\left(\frac{\sigma-1}{\gamma-\sigma+1}\right) \frac{f}{f_{e}} ; \quad D_{2}(k)=\left(\frac{\gamma-\sigma+1}{\gamma}\right) \frac{\beta_{k}}{\sigma f} \\
\gamma=\frac{1}{B_{3 k}}\left[\frac{B_{1 k}\left(\frac{L}{L^{*}}+1\right)}{B_{1 k} B_{2 k} \frac{L}{L^{*}}+1}\right] ; \quad\left(a_{k_{2}}\right)^{\gamma}=\frac{1}{B_{3 k}}\left[\frac{B_{1 k} B_{2 k}}{B_{2 k}\left(\frac{L^{*}}{L}\right.}\right.\end{array}$} \\
\hline
\end{tabular}
A1 below summarizes the equilibrium values of the endogenous variables of the system.

Table A1: Solution of the System

\section{B Proofs of Propositions 3 and 4}

Proof of Proposition 3: 
Following trade liberalization in year $t$, firms with total factor productivity in the interval $\left[\bar{\varphi}_{x k, t+1}, \bar{\varphi}_{x k, t}\right]$ may enter the export market between year $t$ and year $t+1$. The probability of entry into the export market at $t+1$ for a firm in sector $k$ that does not export at $t$ is given by

$$
\operatorname{Pr}(\text { Export entry })=\frac{\left(\bar{\varphi}_{x k, t+1}\right)^{-\gamma}-\left(\bar{\varphi}_{x k, t}\right)^{-\gamma}}{\left(\bar{\varphi}_{d k, t}\right)^{-\gamma}-\left(\bar{\varphi}_{x k, t}\right)^{-\gamma}}=-\left[\frac{\left(\bar{\varphi}_{x k, t}\right)^{-\gamma}}{\left(\bar{\varphi}_{d k, t}\right)^{-\gamma}-\left(\bar{\varphi}_{x k, t}\right)^{-\gamma}}\right] d\left[\ln \left(\bar{\varphi}_{x k}\right)^{\gamma}\right]
$$

Hence, the effect of trade liberalization on the probability of a firm entering the export market is equal to $-\left[\frac{\left(\bar{\varphi}_{x k, t}\right)^{-\gamma}}{\left(\bar{\varphi}_{d k, t}\right)^{-\gamma}-\left(\bar{\varphi}_{x k, t}\right)^{-\gamma}}\right] \frac{d\left[\ln \left(\bar{\varphi}_{x k}\right)^{\gamma}\right]}{d \tau_{i k}} d \tau_{i k}=-\left[\frac{B_{3 k}\left(a_{k}\right)^{\gamma}}{\frac{f x}{f} B_{1 k}+B_{2 k}^{-1}-\frac{f x+f}{f} B_{3 k}\left(a_{k}\right)^{\gamma}}\right]\left[\frac{\mu \gamma T^{*}\left(\tau_{i k}\right)^{-\lambda-1}}{T+T^{*}\left(\tau_{i k}\right)^{-\lambda}}\right] d \tau_{i k}$, which is negative and decreases with $B_{3 k}\left(a_{k}\right)^{\gamma}$ (as its magnitude increases with $\left.B_{3 k}\left(a_{k}\right)^{\gamma}\right)$. $\operatorname{Pr}($ Export entry) will be higher for the firms in a sector with higher $B_{3 k}\left(a_{k}\right)^{\gamma}$. Thus, we have Proposition 3 . We use the logit model to test this proposition. We set a dummy variable to be equal to one if the firm becomes exporter from year $t$ to year $t+1$ and zero otherwise, and use it as the dependent variable in the regression.

\section{Proof of Proposition 4:}

The share of export revenue in total revenue is given by $\frac{f_{x} \cdot \theta_{x k}}{f \cdot \theta_{d k}+f_{x} \cdot \theta_{x k}}=\frac{\left(\bar{\varphi}_{x k}\right)^{-\gamma}}{\left(\bar{\varphi}_{d k}\right)^{-\gamma} f / f_{x}+\left(\bar{\varphi}_{x k}\right)^{-\gamma}}=$ $\frac{B_{3 k}\left(a_{k}\right)^{\gamma}-B_{2 k}^{-1}}{B_{1 k}-B_{2 k}^{-1}}$. The effect of trade liberalization on this share is therefore given by

$$
\frac{d\left[\frac{B_{3 k}\left(a_{k}\right)^{\gamma}-B_{2 k}^{-1}}{B_{1 k}-B_{2 k}^{-1}}\right]}{d \tau_{i k}}=-\left[\frac{B_{3 k}\left(a_{k}\right)^{\gamma}}{B_{1 k}-B_{2 k}^{-1}}\right] \frac{\mu \gamma T^{*}\left(\tau_{i k}\right)^{-\lambda-1}}{T+T^{*}\left(\tau_{i k}\right)^{-\lambda}}
$$

which is negative and decreases with $B_{3 k}\left(a_{k}\right)^{\gamma}$. Thus we have Proposition 4 .

\section{Reduction of tariffs on exported-outputs, exported-inputs and imported-outputs}

$$
\begin{aligned}
& \frac{d \ln \left(\bar{\varphi}_{d k}\right)}{d \tau_{x k}}=-\left[\frac{B_{1 k}}{B_{1 k}-B_{3 k}\left(a_{k}\right)^{\gamma}}-\frac{B_{1 k}}{B_{1 k}-B_{2 k}^{-1}}\right] \frac{1}{\tau_{x k}}<0 \\
& \frac{d \ln \left(\bar{\varphi}_{d k}\right)}{d \tau_{i k}^{*}}=\left[\frac{B_{3 k}\left(a_{k}\right)^{\gamma}}{B_{1 k}-B_{3 k}\left(a_{k}\right)^{\gamma}}\right] \frac{\mu T\left(\tau_{i k}^{*}\right)^{-\lambda-1}}{T^{*}+T\left(\tau_{i k}^{*}\right)^{-\lambda}}>0 \\
& \frac{d \ln \left(\bar{\varphi}_{d k}\right)}{d \tau_{x k}^{*}}=\left(\frac{1}{B_{1 k} B_{2 k}-1}\right) \frac{1}{\tau_{x k}^{*}}>0
\end{aligned}
$$




$$
\begin{aligned}
& \frac{d \ln \left(\bar{\varphi}_{x k}\right)}{d \tau_{x k}}=\left(\frac{B_{2 k}}{B_{2 k}-B_{1 k}^{-1}}\right) \frac{1}{\tau_{x k}}>0 \\
& \frac{d \ln \left(\bar{\varphi}_{x k}\right)}{d \tau_{i k}^{*}}=-\left[\frac{B_{2 k}}{B_{2 k}-B_{3 k}^{-1}\left(a_{k}\right)^{-\gamma}}\right] \frac{\mu T\left(\tau_{i k}^{*}\right)^{-\lambda-1}}{T^{*}+T\left(\tau_{i k}^{*}\right)^{-\lambda}}<0 \\
& \frac{d \ln \left(\bar{\varphi}_{x k}\right)}{d \tau_{x k}^{*}}=-\left[\frac{B_{2 k}}{B_{2 k}-B_{3 k}^{-1}\left(a_{k}\right)^{-\gamma}}-\frac{B_{2 k}}{B_{2 k}-B_{1 k}^{-1}}\right] \frac{1}{\tau_{x k}^{*}}<0 \\
& \frac{d\left(\frac{\bar{\varphi}_{d k}}{\bar{\varphi}_{x k}}\right)^{\gamma}}{d \tau_{x k}}=-\frac{f}{f_{x}}\left[\frac{B_{1 k}\left(B_{3 k}\left(a_{k}\right)^{\gamma}-B_{2 k}^{-1}\right)}{\left(B_{1 k}-B_{3 k}\left(a_{k}\right)^{\gamma}\right)^{2}}\right] \frac{\gamma}{\tau_{x k}}<0 \\
& \frac{d\left(\frac{\bar{\varphi}_{d k}}{\bar{\varphi}_{x k}}\right)^{\gamma}}{d \tau_{i k}^{*}}=\frac{f}{f_{x}}\left[\frac{\left(B_{1 k}-B_{2 k}^{-1}\right) B_{3 k}\left(a_{k}\right)^{\gamma}}{\left(B_{1 k}-B_{3 k}\left(a_{k}\right)^{\gamma}\right)^{2}}\right] \frac{\mu \gamma T\left(\tau_{i k}^{*}\right)^{-\lambda-1}}{T^{*}+T\left(\tau_{i k}^{*}\right)^{-\lambda}}>0 \\
& \frac{d\left(\frac{\bar{\varphi}_{d k}}{\bar{\varphi}_{x k}}\right)^{\gamma}}{d \tau_{x k}^{*}}=\frac{f}{f_{x}}\left[\frac{B_{2 k}^{-1}}{B_{1 k}-B_{3 k}\left(a_{k}\right)^{\gamma}}\right] \frac{\gamma}{\tau_{x k}^{*}}>0
\end{aligned}
$$

In each case, the magnitude of the effect on $\left(\frac{\bar{\varphi}_{d k}}{\bar{\varphi}_{x k}}\right)^{\gamma}$ is larger, the larger is $B_{3 k}\left(a_{k}\right)^{\gamma}$.

\section{Other Tables}

Table A2: The correlation among different RCA

\begin{tabular}{|l|c|c|c|c|c|||r|c|c|c|c|c|}
\hline \multicolumn{5}{|c||}{ Panel A - correlation coefficients } & \multicolumn{5}{c|}{ Panel B - log rank correlation coefficients } \\
\hline & $\mathrm{RCA}_{1}$ & $\mathrm{RCA}_{2}$ & $\mathrm{RCA}_{3}$ & $\mathrm{RCA}_{4}$ & $\mathrm{RCA}_{5}$ & & $\mathrm{RCA}_{1}$ & $\mathrm{RCA}_{2}$ & $\mathrm{RCA}_{3}$ & $\mathrm{RCA}_{4}$ & $\mathrm{RCA}_{5}$ \\
\hline $\mathrm{RCA}_{1}$ & 1.000 & & & & & $\mathrm{RCA}_{1}$ & 1.000 & & & & \\
\hline $\mathrm{RCA}_{2}$ & 0.939 & 1.000 & & & & $\mathrm{RCA}_{2}$ & 0.551 & 1.000 & & & \\
\hline $\mathrm{RCA}_{3}$ & 0.588 & 0.748 & 1.000 & & & $\mathrm{RCA}_{3}$ & 0.687 & 0.946 & 1.000 & & \\
\hline $\mathrm{RCA}_{4}$ & 0.802 & 0.847 & 0.571 & 1.000 & & $\mathrm{RCA}_{4}$ & 0.687 & 0.946 & 1.000 & 1.000 & \\
\hline $\mathrm{RCA}_{5}$ & 0.687 & 0.837 & 0.972 & 0.735 & 1.000 & $\mathrm{RCA}_{5}$ & 0.687 & 0.946 & 1.000 & 1.000 & 1.000 \\
\hline
\end{tabular}

Table A2: Panel C

\begin{tabular}{|c|c|c|c|c|}
\hline \multicolumn{5}{|c|}{ Table A2: Panel C } \\
\hline \multicolumn{5}{|c|}{ Summary statistics of the RCA } \\
\hline Variable & Mean & Median & Min & Max \\
\hline $\mathrm{RCA}_{1}$ & 1.365 & 0.756 & 0.029 & 9.254 \\
\hline $\mathrm{RCA}_{2}$ & 0.416 & -0.004 & -3.314 & 9.029 \\
\hline $\mathrm{RCA}_{3}$ & 0.283 & 0.363 & -0.864 & 0.965 \\
\hline $\mathrm{RCA}_{4}$ & 2.610 & 1.010 & 0.034 & 26.50 \\
\hline $\mathrm{RCA}_{5}$ & 5.269 & 1.006 & -337.21 & 327.72 \\
\hline
\end{tabular}




\begin{tabular}{|c|c|c|c|c|c|c|c|c|}
\hline \multicolumn{9}{|c|}{ Table A3: Probability of entry into the export market } \\
\hline RCA index & $\mathrm{RCA}_{1}$ & $\mathrm{RCA}_{2}$ & $\mathrm{RCA}_{3}$ & $\mathrm{RCA}_{4}$ & $\mathrm{RCA}_{5}$ & $\operatorname{Rank}_{1}$ & $\mathrm{Rank}_{2}$ & $\mathrm{Rank}_{3}$ \\
\hline \multirow[t]{2}{*}{ Regressor } & Logit & Logit & Logit & Logit & Logit & Logit & Logit & Logit \\
\hline & (1) & $(2)$ & $(3)$ & (4) & $(5)$ & (6) & (7) & (8) \\
\hline \multirow[t]{2}{*}{$\Delta$ duty $_{i k}$} & 0.630 & -0.003 & -0.184 & 0.684 & -0.960 & $2.627^{* *}$ & 4.013 & $3.822^{* *}$ \\
\hline & $(0.439)$ & $(0.441)$ & $(0.499)$ & $(0.426)$ & $(0.618)$ & $(1.201)$ & $(2.765)$ & $(1.929)$ \\
\hline \multirow[t]{2}{*}{$\Delta$ duty $_{i k} \times \mathbf{R C A}$} & $-1.026^{* *}$ & $-0.954^{* *}$ & $-2.574^{* *}$ & $-0.755^{* * *}$ & $-0.013^{* *}$ & $-1.436^{* * *}$ & -1.274 & $-1.432^{* *}$ \\
\hline & $(0.460)$ & $(0.460)$ & $(1.230)$ & $(0.099)$ & $(0.006)$ & $(0.552)$ & $(0.907)$ & $(0.657)$ \\
\hline \multirow[t]{2}{*}{$\Delta$ duty $_{o k}$} & 1.098 & 1.243 & 0.942 & 1.064 & 0.954 & 0.198 & 1.286 & 1.130 \\
\hline & $(0.865)$ & $(0.863)$ & $(0.919)$ & $(0.880)$ & $(0.911)$ & $(1.024)$ & $(0.893)$ & $(0.910)$ \\
\hline \multirow[t]{2}{*}{$\mathrm{RCA}$} & $0.112^{* *}$ & $0.113^{* * *}$ & $0.457^{* * *}$ & $0.052^{*}$ & $0.002^{* * *}$ & $0.323^{* * *}$ & $0.259^{* * *}$ & $0.237^{* * *}$ \\
\hline & $(0.047)$ & $(0.033)$ & $(0.153)$ & $(0.029)$ & $(0.001)$ & $(0.082)$ & $(0.066)$ & $(0.081)$ \\
\hline \multirow[t]{2}{*}{ TFP } & $0.039^{* *}$ & $0.040 * *$ & $0.039^{* *}$ & $0.038^{*}$ & $0.039^{* *}$ & $0.040^{* *}$ & $0.039^{* *}$ & $0.038^{* *}$ \\
\hline & $(0.020)$ & $(0.020)$ & $(0.019)$ & $(0.020)$ & $(0.019)$ & $(0.019)$ & $(0.019)$ & $(0.019)$ \\
\hline \multirow[t]{2}{*}{$\log (\mathrm{Empl})$} & $0.296^{* * *}$ & $0.299 * * *$ & $0.301^{* * *}$ & $0.295^{* * *}$ & $0.300^{* * *}$ & $0.300^{* * *}$ & $0.304^{* * *}$ & $0.300^{* * *}$ \\
\hline & $(0.019)$ & $(0.018)$ & $(0.019)$ & $(0.019)$ & $(0.019)$ & $(0.019)$ & $(0.018)$ & $(0.019)$ \\
\hline \multirow[t]{2}{*}{$\log (\mathrm{K} / \mathrm{L})$} & 0.024 & 0.026 & 0.026 & 0.024 & 0.026 & 0.027 & 0.026 & 0.026 \\
\hline & $(0.018)$ & $(0.018)$ & $(0.018)$ & $(0.018)$ & $(0.018)$ & $(0.018)$ & $(0.018)$ & $(0.018)$ \\
\hline \multirow[t]{2}{*}{$\log ($ Wage $)$} & $0.291 * * *$ & $0.288^{* * *}$ & $0.287^{* * *}$ & $0.293^{* * *}$ & $0.288^{* * *}$ & $0.292^{* * *}$ & $0.284^{* * *}$ & $0.290^{* * *}$ \\
\hline & $(0.027)$ & $(0.026)$ & $(0.027)$ & $(0.026)$ & $(0.027)$ & $(0.026)$ & $(0.027)$ & $(0.027)$ \\
\hline Year fixed effect & Yes & Yes & Yes & Yes & Yes & Yes & Yes & Yes \\
\hline Industry fixed effect & Yes & Yes & Yes & Yes & Yes & Yes & Yes & Yes \\
\hline Observations & 364827 & 364827 & 364827 & 364827 & 364827 & 364827 & 364827 & 364827 \\
\hline Log likelihood & -78700 & -78640 & -78676 & -78648 & -78647 & -78568 & -78665 & -78707 \\
\hline
\end{tabular}




\begin{tabular}{|c|c|c|c|c|c|c|c|c|}
\hline \multicolumn{9}{|c|}{ Table A4: Change in fraction of exporting firms } \\
\hline RCA index & $\mathrm{RCA}_{1}$ & $\mathrm{RCA}_{2}$ & $\mathrm{RCA}_{3}$ & $\mathrm{RCA}_{4}$ & $\mathrm{RCA}_{5}$ & $\operatorname{Rank}_{1}$ & $\mathrm{Rank}_{2}$ & Rank$_{3}$ \\
\hline \multirow[t]{2}{*}{ Regressor } & OLS & OLS & OLS & OLS & OLS & OLS & OLS & OLS \\
\hline & (1) & $(2)$ & (3) & $(4)$ & $(5)$ & (6) & (7) & (8) \\
\hline \multirow[t]{2}{*}{$\Delta$ duty $_{i k}$} & 0.002 & $-0.057^{* *}$ & $-0.041^{*}$ & 0.007 & $-0.068^{* *}$ & 0.030 & $0.213^{*}$ & 0.043 \\
\hline & $(0.021)$ & $(0.028)$ & $(0.023)$ & $(0.027)$ & $(0.032)$ & $(0.038)$ & $(0.125)$ & $(0.053)$ \\
\hline \multirow[t]{2}{*}{$\Delta$ duty $_{i k} \times \mathbf{R C A}$} & $-0.099^{* * *}$ & $-0.089^{* * *}$ & $-0.072^{*}$ & $-0.047^{* *}$ & $-0.0004^{*}$ & $-0.038^{*}$ & $-0.077^{*}$ & -0.028 \\
\hline & $(0.035)$ & $(0.033)$ & $(0.044)$ & $(0.021)$ & $(0.0002)$ & $(0.021)$ & $(0.041)$ & $(0.022)$ \\
\hline \multirow[t]{2}{*}{$\Delta$ duty $_{o k}$} & -0.011 & -0.006 & -0.012 & -0.016 & -0.023 & 0.116 & 0.076 & 0.095 \\
\hline & $(0.037)$ & $(0.037)$ & $(0.038)$ & $(0.037)$ & $(0.050)$ & $(0.082)$ & $(0.158)$ & $(0.176)$ \\
\hline \multirow[t]{2}{*}{$\mathrm{RCA}$} & $-0.002^{*}$ & -0.000 & $0.008^{* *}$ & -0.000 & 0.000 & -0.002 & $0.003^{*}$ & 0.003 \\
\hline & $(0.001)$ & $(0.001)$ & $(0.004)$ & $(0.001)$ & $(0.000)$ & $(0.002)$ & $(0.002)$ & $(0.002)$ \\
\hline \multirow[t]{2}{*}{ TFP } & $0.013^{* * *}$ & $0.013^{* * *}$ & $0.012^{* * *}$ & $0.013^{* * *}$ & $0.013^{* * *}$ & $0.013^{* * *}$ & $0.012^{* * *}$ & $0.013^{* * *}$ \\
\hline & $(0.004)$ & $(0.004)$ & $(0.004)$ & $(0.004)$ & $(0.004)$ & $(0.004)$ & $(0.004)$ & $(0.004)$ \\
\hline \multirow[t]{2}{*}{$\log (\mathrm{Empl})$} & $-0.003^{* * *}$ & $-0.003^{* * *}$ & $-0.003^{* * *}$ & $-0.003^{* * *}$ & $-0.003^{* * *}$ & $-0.003^{* * *}$ & $-0.003^{* * *}$ & $-0.003^{* * *}$ \\
\hline & $(0.001)$ & $(0.001)$ & $(0.001)$ & $(0.001)$ & $(0.001)$ & $(0.001)$ & $(0.001)$ & $(0.001)$ \\
\hline \multirow[t]{2}{*}{$\log (\mathrm{K} / \mathrm{L})$} & 0.000 & 0.000 & 0.001 & 0.000 & 0.001 & -0.000 & 0.001 & 0.001 \\
\hline & $(0.002)$ & $(0.002)$ & $(0.002)$ & $(0.002)$ & $(0.002)$ & $(0.002)$ & $(0.003)$ & $(0.002)$ \\
\hline \multirow[t]{2}{*}{$\log$ (Wage) } & $-0.010^{*}$ & -0.010 & -0.010 & $-0.010^{*}$ & $-0.010^{*}$ & -0.009 & -0.010 & -0.010 \\
\hline & $(0.006)$ & $(0.006)$ & $(0.006)$ & $(0.006)$ & $(0.006)$ & $(0.006)$ & $(0.006)$ & $(0.006)$ \\
\hline Year fixed effect & Yes & Yes & Yes & Yes & Yes & Yes & Yes & Yes \\
\hline Industry fixed effect & Yes & Yes & Yes & Yes & Yes & Yes & Yes & Yes \\
\hline Observations & 2018 & 2018 & 2018 & 2018 & 2018 & 2018 & 2018 & 2018 \\
\hline R-squared & 0.065 & 0.065 & 0.061 & 0.065 & 0.062 & 0.061 & 0.061 & 0.060 \\
\hline \multicolumn{9}{|c|}{ Note: ${ }^{* * *}$ Significant at the $1 \%$ level; ${ }^{* *}$ Significant at the $5 \%$ level; ${ }^{*}$ Significant at the $10 \%$ level. } \\
\hline & & & & & & & & \\
\hline
\end{tabular}




\begin{tabular}{|c|c|c|c|c|c|c|c|c|}
\hline \multicolumn{9}{|c|}{ Table A5: Change in share of export revenue in total revenue } \\
\hline RCA index & $\mathrm{RCA}_{1}$ & $\mathrm{RCA}_{2}$ & $\mathrm{RCA}_{3}$ & $\mathrm{RCA}_{4}$ & $\mathrm{RCA}_{5}$ & $\operatorname{Rank}_{1}$ & $\operatorname{Rank}_{2}$ & $\mathrm{Rank}_{3}$ \\
\hline \multirow[t]{2}{*}{ Regressor } & OLS & OLS & OLS & OLS & OLS & OLS & OLS & OLS \\
\hline & $(1)$ & $(2)$ & $(3)$ & $(4)$ & $(5)$ & (6) & $(7)$ & $(8)$ \\
\hline \multirow[t]{2}{*}{$\Delta$ duty $_{i k}$} & -0.000 & $-0.055^{* *}$ & $-0.045^{*}$ & 0.004 & $-0.084^{* *}$ & $0.054^{*}$ & $0.320^{* *}$ & 0.077 \\
\hline & $(0.016)$ & $(0.026)$ & $(0.024)$ & $(0.019)$ & $(0.034)$ & $(0.029)$ & $(0.133)$ & $(0.054)$ \\
\hline \multirow[t]{2}{*}{$\Delta$ duty $_{i k} \times \mathbf{R C A}$} & $-0.091^{* * *}$ & $-0.087^{* * *}$ & $-0.105^{* *}$ & $-0.044^{* * *}$ & $-0.001^{* *}$ & $-0.051^{* *}$ & $-0.112^{* *}$ & -0.039 \\
\hline & $(0.033)$ & $(0.029)$ & $(0.048)$ & $(0.015)$ & $(0.0002)$ & $(0.023)$ & $(0.044)$ & $(0.024)$ \\
\hline \multirow[t]{2}{*}{$\Delta$ duty $_{o k}$} & 0.013 & 0.021 & 0.011 & 0.010 & 0.011 & 0.005 & 0.028 & $0.550^{* * *}$ \\
\hline & $(0.054)$ & $(0.053)$ & $(0.054)$ & $(0.054)$ & $(0.054)$ & $(0.057)$ & $(0.054)$ & $(0.192)$ \\
\hline \multirow[t]{2}{*}{$\mathrm{RCA}$} & -0.000 & 0.001 & $0.011^{* * *}$ & 0.001 & $0.000 * * *$ & 0.001 & $0.004^{* *}$ & 0.002 \\
\hline & $(0.002)$ & $(0.001)$ & $(0.004)$ & $(0.001)$ & $(0.000)$ & $(0.002)$ & $(0.002)$ & $(0.002)$ \\
\hline \multirow[t]{2}{*}{$\mathrm{TFP}$} & 0.004 & 0.003 & 0.003 & 0.004 & 0.004 & 0.004 & 0.003 & 0.003 \\
\hline & $(0.004)$ & $(0.004)$ & $(0.004)$ & $(0.004)$ & $(0.004)$ & $(0.004)$ & $(0.004)$ & $(0.004)$ \\
\hline \multirow[t]{2}{*}{$\log (\mathrm{Empl})$} & $-0.005^{* * *}$ & $-0.005^{* * *}$ & $-0.005^{* * *}$ & $-0.005^{* * *}$ & $-0.005^{* * *}$ & $-0.005^{* * *}$ & $-0.005^{* * *}$ & $-0.005^{* * *}$ \\
\hline & $(0.001)$ & $(0.001)$ & $(0.001)$ & $(0.001)$ & $(0.001)$ & $(0.001)$ & $(0.001)$ & $(0.001)$ \\
\hline \multirow[t]{2}{*}{$\log (\mathrm{K} / \mathrm{L})$} & $0.007^{* * *}$ & $0.007^{* * *}$ & $0.008^{* * *}$ & $0.007^{* * *}$ & $0.008^{* * *}$ & $0.007^{* * *}$ & $0.008^{* * *}$ & $0.008^{* * *}$ \\
\hline & $(0.002)$ & $(0.002)$ & $(0.002)$ & $(0.002)$ & $(0.002)$ & $(0.002)$ & $(0.002)$ & $(0.002)$ \\
\hline \multirow[t]{2}{*}{$\log ($ Wage $)$} & -0.001 & -0.001 & -0.001 & -0.002 & -0.001 & -0.001 & -0.001 & -0.000 \\
\hline & $(0.007)$ & $(0.007)$ & $(0.007)$ & $(0.007)$ & $(0.007)$ & $(0.007)$ & $(0.007)$ & $(0.007)$ \\
\hline Year fixed effect & Yes & Yes & Yes & Yes & Yes & Yes & Yes & Yes \\
\hline Industry fixed effect & Yes & Yes & Yes & Yes & Yes & Yes & Yes & Yes \\
\hline Observations & 2018 & 2018 & 2018 & 2018 & 2018 & 2018 & 2018 & 2018 \\
\hline R-squared & 0.061 & 0.062 & 0.060 & 0.062 & 0.061 & 0.057 & 0.059 & 0.062 \\
\hline \multicolumn{9}{|c|}{ Note: ${ }^{* * *}$ Significant at the $1 \%$ level; ${ }^{* *}$ Significant at the $5 \%$ level; ${ }^{*}$ Significant at the $10 \%$ level. } \\
\hline-1 & 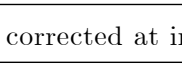 & 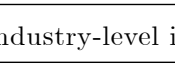 & & & & & & \\
\hline
\end{tabular}




\section{References}

[1] Ackerberg, Daniel, Kevin Caves, and Garth Frazer, "Structural identification of production functions", MPRA Working Paper (2006)

[2] Alvarez, Roberto and Ricardo A. Lopez, "Trade Liberalization and Industry Dynamics", Open Economies Review, 23(4), 579-595 (2012)

[3] Amiti, Mary, and Amit Khandelwal, "Import Competition and Quality Upgrading", Review of Economics and Statistics, 95(2), 476-490 (2013)

[4] Amiti, Mary and Jozef Konings, "Trade Liberalization, Intermediate Inputs, and Productivity: Evidence from Indonesia", American Economic Review, 97(5), 1611-1638 (2007)

[5] Antras, Pol, Teresa Fort, and Felix Tintelnot, "The Margins of Global Sourcing: Theory and Evidence from U.S. Firms", Working Paper (2014)

[6] Balassa, Bela, "Trade Liberalization and Revealed Comparative Advantage", Manchester School of Economic and Social Studies, 33(2), 99-103 (1965)

[7] Bas, Maria, and Vanessa Strauss-Kahn, "Input-trade liberalization, export prices and quality upgrading", Journal of International Economics, 95(2), 250-262 (2015)

[8] Bernard, Andrew B., Stephen J. Redding and Peter K. Schott, "Comparative Advantage and Heterogeneous Firms", Review of Economic studies, 74(1), 31-66 (2007)

[9] Bombardini, Matilde, Chris Kurz and Peter Michaels Morrow, "Ricardian Trade and the Impact of Domestic Competition on Export Performance", Canadian Journal of Economics, 45(2), 1585-1612 (2012)

[10] Brandt, Loren, Johannes Van Biesebroeck and Yifan Zhang, "Creative Accounting or Creative Destruction? Firm-level Productivity Growth in Chinese Manufacturing", Journal of Development Economics 97(2), 339-351 (2012)

[11] Cai, Hongbin and Qiao Liu, "Competition and Corporate Tax Avoidance: Evidence from Chinese Industrial Firms", Economic Journal, 119(4), 764-795 (2009)

[12] De Loecker, Jan, Pinelopi Goldberg, Amit Khandelwal, and Nina Pavcnik, "Prices, Markup and Trade Reforms", Econometrica, forthcoming (2015)

[13] Eaton, Jonathan and Samuel Kortum, "Technology, Geography and Trade", Econometrica 70(5), 1741-1779 (2002)

[14] Fan, Haichao, Yao Amber Li, and Stephen Yeaple, "Trade Liberalization, Quality, and Export Prices", Review of Economics and Statistics, 97(5), 1033-1051 (2015)

[15] Fan, Haichao, Xiang Gao, Yao Amber Li, and Tuan Anh Luong, "Trade Liberalization and Markups: Micro Evidence from China", Working Paper (2015) 
[16] Feenstra, Robert C, Zhiyuan Li, and Miaojie Yu, "Exports and Credit Constraints under Incomplete Information: Theory and Evidence from China", Review of Economics and Statistics, 96(4), 729$744(2014)$

[17] Goldberg, Pinelopi, Amit Khandelwal, Nina Pavcnik, and Petia Topalova, "Imported Intermediate Inputs and Domestic Product Growth: Evidence from India", Quarterly Journal of Economics, 125(4), 1727-1767 (2010)

[18] Gopinath, Gita and Brent Neiman, "Trade Adjustment and Productivity in Large Crises", American Economic Review, 104(3), 793-831 (2014)

[19] Halpern, Laszlo, Miklos Koren, and Adam Szeidl, "Imported Inputs and Productivity", CeFiG Working Papers (2011)

[20] Johnson, Robert C. and Guillermo Noguera, "Fragmentation and Trade in Value Added Over Four Decades", Working Paper (2012)

[21] Koopman, Robert, Zhi Wang, and Shang-Jin Wei, "Tracing Value-Added and Double Counting in Gross Exports", American Economic Review, 104(2), 459-94 (2014)

[22] Levinsohn, James and Amil Petrin, "Estimating Production Functions Using Inputs to Control for Unobservables", The Review of Economic Studies, 70(2), 317-341 (2003)

[23] Melitz, Marc J., "The Impact of Trade on Intraindustry Reallocations and Aggregate Industry Productivity", Econometrica 71(6), 1695-1725 (2003)

[24] Olley, G. Steven and Ariel Pakes, "The Dynamics of Productivity in the Telecommunications Equipment Industry", Econometrica, 64(6), 1263-1297 (1996)

[25] Okubo, Toshihiro, "Firm Heterogeneity and Ricardian Comparative Advantage within and across Sectors", Economic Theory, 38(3), 533-559 (2009)

[26] Yu, Miaojie, "Processing Trade, Tariff Reductions and Firm Productivity: Evidence from Chinese Firms", Economic Journal, 125, 943-988 (2015) 